\title{
HOURS WORKED BY GENERAL PRACTITIONERS AND WAITING TIMES FOR PRIMARY CARE
}

Text (excluding refs, tables): 5,082 words. Abstract: 109 words.

Table count: 5

Figure count: 2

Authors: Megha Swami ${ }^{\text {a, }}{ }^{\text {, }}$ Hugh Gravelle ${ }^{c}$, Anthony Scott ${ }^{a}$, Jenny Williams ${ }^{\text {b }}$

${ }^{a}$ Melbourne Institute of Applied Economic and Social Research, University of Melbourne

${ }^{\mathrm{b}}$ Department of Economics, University of Melbourne

${ }^{\mathrm{c}}$ Centre for Health Economics, University of York, UK

Corresponding Author: Megha Swami

Address: Faculty of Business and Economics (FBE), University of Melbourne, 111 Barry Street, Carlton

VIC 3053, Australia

Email: mswami@student.unimelb.edu.au

\begin{abstract}
The decline in the working hours of general practitioners (GPs) is a key factor influencing access to healthcare in many countries. We investigate the effect of changes in hours worked by general practitioners (GPs) on waiting times in primary care using the MABEL longitudinal survey of Australian doctors. We estimate GP fixed effects models for waiting time and use family circumstances to instrument for GP's hours worked. We find that a $10 \%$ reduction in hours worked increases average patient waiting time by $12 \%$. Our findings highlight the importance of GPs' labour supply at the intensive margin in determining the length of time patients must wait to see their doctor.
\end{abstract}

Keywords: primary care; waiting times; labour supply; fixed-effects; Instrumental Variable model; MABEL Survey

\section{Acknowledgements}

This study used data from the MABEL longitudinal survey of doctors conducted by the University of Melbourne and Monash University (the MABEL research team). Funding for MABEL comes from the National Health and Medical Research Council (Health Services Research Grant: 2008-2011; and Centre for Research Excellence in Medical Workforce Dynamics: 2012-2017) with additional support from the Department of Health in 2008) and Health Workforce Australia (in 2013). Megha Swami's PhD study was supported by Melbourne Research Scholarship from the University of Melbourne. The authors would like to thank two anonymous referees, participants of the $22^{\text {nd }}$ International Panel Data Conference and $29^{\text {th }} \mathrm{PhD}$ Conference in Economics and Business for helpful comments, and Tamara Taylor, the MABEL Data Manager, for assistance with the Survey data. The MABEL research team bears no responsibility for how the data has been analyzed, used or summarized in this research.

This is the author manuscript accepted for publication and has undergone full peer review but

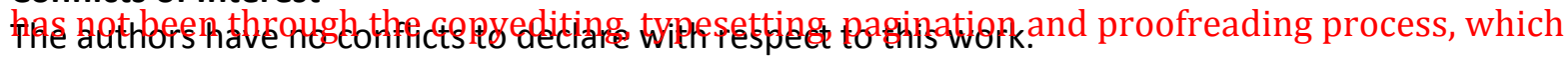
may lead to differences between this version and the Version of Record. Please cite this article as doi: $10.1002 /$ hec.3782 


\section{Introduction}

Primary health care is typically the first point of contact with the health care system and plays an important role in the diagnosis and management of patients' health problems. Concerns about access to primary health care services have been growing in many countries (Sarma, Thind, \& Chu, 2011). In healthcare markets where there is public or private insurance and patients face zero or below market clearing prices, demand is rationed by waiting times. Consequently, waiting times are a key measure of access to health care (Siciliani \& Hurst, 2003). Delays in receiving primary care results not only in the risk of deterioration of patients' health but also an increase in hospital or emergency department use (Bindman et al., 1995; Cowling et al., 2013; Dolton \& Pathania, 2016).

An increased prevalence of chronic diseases and ageing populations have led to an increase in the demand for primary care services in many OECD countries. At the same time, hours worked by general practitioners (GPs) have declined (Crossley, Hurley, \& Jeon, 2009; Kirch \& Vernon,

This article is protected by copyright. All rights reserved. 
2008; Sarma et al., 2011). Young doctors are working fewer hours than previous cohorts (Sarma et al., 2011) and there has been a decline in the hours GPs work, both overall and in direct patient care for males and female GPs (H. Britt et al., 2013; Crossley et al., 2009). Reductions in hours worked are primarily attributed to the increasing proportion of female doctors, the ageing of the medical workforce and a shift of preferences over work-life balance (Crossley et al., 2009; Joyce, McNeil, \& Stoelwinder, 2006; Kirch \& Vernon, 2008; Shrestha \& Joyce, 2011). There is currently little knowledge of how these changes in GP labour supply affect access to primary care in general and waiting times in particular. Medical training is a lengthy and costly process, and there are licensing restrictions on entry into the medical profession, so compared to other labour markets, supply at the extensive margin is relatively inflexible to short term changes in demand. As a result, reductions in working hours may have important implications for access to primary care services.

In this paper, we use a longitudinal survey of Australian doctors to investigate the extent to which hours worked by GPs affect waiting times for appointments. Waiting times for primary care are a policy concern in several OECD countries including Australia, Canada, U.K. and Sweden (Siciliani, Borowitz, \& Moran, 2013), but are less studied than hospital waiting times (Cullis \& Jones, 1986; Goddard, Malek, \& Tavakoli, 1995; Gravelle, Smith, \& Xavier, 2003; Iversen, 1993; Lindsay \& Feigenbaum, 1984; Martin \& Smith, 1999). The limited literature examining the accessibility to primary care focuses on differences in access by patient age, gender, location and health (Kontopantelis, Roland, \& Reeves, 2010; Muggah et al., 2014; Young, Dobson, \& Byles, 2000). The few studies of primary care waiting times find that patients with higher income and private insurance have shorter waiting times (Roll, Stargardt, \& Schreyögg, 2012). There is a paucity of research on how waiting times in primary care are affected by supply-side factors which is crucial in designing policies to ensure timely access to GP services.

Our study is the first to examine the impact of hours worked by GPs on the length of time patients wait to see them. The key challenge in identifying the causal impact of hours worked by GPs on waiting times is the potential for unobserved confounders that determine both labour supply of GPs and their patients' waiting time. This is an issue because failing to account 
for confounders will lead to biased estimates of the impact of hours worked on waiting times. We address the presence of time-invariant confounders, such as GPs' motivation and ability, using a GP fixed effects (FE) approach. In order to also account for time-varying unobserved confounders, such as changes in patient case mix, we implement a fixed effect instrumental variables (FEIV) estimation strategy. After accounting for both time invariant and time-varying unobserved confounding, we find that waiting times do respond to hours worked by GPs: a $10 \%$ decrease in the average hours worked by a GP will increase the average waiting time for the GP by $12 \%$. We also find that waiting times are affected by GP attributes such as education and experience, local GP density, and by the socioeconomic status of the local population.

In Section 2 we briefly set out the institutional context, provide a simple model of waiting time and GP labour supply, and use it to guide our estimation strategy. Section 3 describes the data and Section 4 provides the estimation results. Section 5 concludes with a discussion of the results and policy implications.

\section{Methods}

\subsection{General practitioners in Australia}

In Australia, GPs are the most commonly accessed primary health service and act as gatekeepers to specialist care. Eighty-three percent of Australians consulted a GP at least once in the previous 12 months in 2016-17 (Australian Bureau of Statistics, 2017). Medicare, Australia's tax-financed public insurance scheme, provides a fixed subsidy for each visit to a medical practitioner. GPs can charge fees at or above the rebate, which thus acts as a floor price. Medicare provides financial incentives to GPs to set their fees equal to the rebate for Commonwealth Concession Card holders and children under 16 years of age (Department of Human Services, 2015a), with higher incentives in regional, rural and remote areas (Department of Human Services, 2016). ${ }^{1}$ When they do so, the full cost of GP services is billed

\footnotetext{
${ }^{1}$ Concession cards reduce the fees paid by patients for Pharmaceutical Benefits Scheme prescription items, and certain Medicare services. There are six types of concession cards provided by the government - Health Care Card, Commonwealth Seniors Health Card, Low Income Health Care Card, Pensioner Concession Card, Ex-Carer Allowance (Child) Health Care Card,
} 
directly to Medicare and patients have no out of pocket costs. This practice is known as bulkbilling. Over eighty percent of GP services are bulk-billed (Department of Health, 2017). Some practices bulk-bill all or most of their patients and others bulk-bill only a small proportion of their patients, typically in more affluent areas (Gravelle, Scott, Sivey, \& Yong, 2016). Patients are free to visit any GP as there is no compulsory patient list or registration system. Most GPs work in privately owned group practices with other GPs, practice nurses and allied health professionals. In 2015-16, around 67 percent of GPs were working in practices of five or more GPs, and on average, there were 7.5 GPs per practice (H. Britt et al., 2016).

\subsection{Waiting time and GP hours worked}

We outline a simple model of the market for GP consultations. ${ }^{2}$ Given high bulk-billing rates, we assume that the GP bulk-bills all patients, who therefore face a zero price. ${ }^{3}$

Demand for consultations with the GP is:

$$
D=D\left(w, q ; x_{d}, \epsilon_{d}\right), \quad D_{w}<0, D_{q}>0
$$

where $w$ is waiting time and $q$ is a measure of the GP's quality. $x_{d}$ is a vector of exogenous demand shifters - such as income, education, health status and the age-distribution of the local population. It also includes other exogenous factors such as availability of emergency departments and other GPs. $\epsilon_{d}$ captures unmeasured factors that shift demand.

On the supply side, GP works $h$ hours per week. We assume that consultation length $t$ is fixed so that the supply of consultations per week is $n=h / t$. The assumption that consultation length is fixed is reasonable in the Australian context given that most general practices follow a fixed

\footnotetext{
Foster Child Care Card. For more details see: https://www.humanservices.gov.au/customer/subjects/concession-and-healthcare-cards

${ }^{2}$ See Cheraghi-Sohi et al., 2008; Gandhi, Parle, Greenfield, \& Gould, 1997; Gerard, Salisbury, Street, Pope, \& Baxter, 2008; Gravelle et al., 2003; Martin, Jacobs, Rice, \& Smith, 2003; Scott, 2000; Scott \& Vick, 1999; Scott, Watson, \& Ross, 2003; Turner et al., 2007 for related literature and theoretical models.

${ }^{3}$ We test the sensitivity of our results to this assumption in section 4.2 .
} 
appointment scheduling system where patients are booked for 15-20 minutes' appointments with the GPs for a standard (level B) consultation. ${ }^{4}$

The GP bulk-bills all patients and so receives a fixed Medicare rebate $m$ per patient. She incurs costs $c\left(n, q ; x_{c}, \epsilon_{c}\right)$ where $x_{c}$ are observed factors affecting costs such as the costs of nurses, allied health and administrative staff, and patient complexity. $\epsilon_{c}$ is an unobserved component. GP income is $y=y^{0}+m n-c\left(n, q ; x_{c}, \epsilon_{c}\right)$, where $y^{0}$ is exogenous non-work income. The utility of the GP is:

$$
u=u\left(y, h ; x_{g}, \epsilon_{g}\right)
$$

where $x_{g}$ denote GP's personal characteristics such as age, gender, children, etc., and $\epsilon_{g}$ is an unobserved preference shifter. The GP chooses her hours $h=n t$ of work to satisfy

$$
u_{h}+u_{y}\left(\frac{m}{t}-c_{n} \frac{1}{t}\right)=0
$$

and so

$$
h=h^{*}\left(m, t, q, x_{c}, x_{g}, \epsilon_{c}, \epsilon_{g}\right)
$$

Equivalently, given the fixed consultation length, the GP supplies consultations to the point where their marginal cost, including the monetary value of forgone leisure, equals marginal revenue $(m)$.

$$
m=c_{n}-t \frac{u_{h}}{u_{y}}
$$

as in the top panel in Figure 1. The supply of consultations is:

$$
n=h^{*}\left(m, t, q, x_{c}, x_{g}, \epsilon_{c}, \epsilon_{g}\right) / t=n^{*}\left(m, t, q, x_{c}, x_{g}, \epsilon_{c}, \epsilon_{g}\right)
$$

\footnotetext{
${ }^{4}$ Evidence from Australia as well as United states and Europe indicates that consultation length is determined to a large extent by the nature of the problems managed during the consultation and the characteristics of the patients such as age and gender (H. C. Britt, Valenti, \& Miller, 2005; Deveugele, Derese, van den Brink-Muinen, Bensing, \& De Maeseneer, 2002; Sayer et al., 2000). It is also affected by GP characteristics such as age, gender and medical training, and by practice type and location (Bensing, Roter, \& Hulsman, 2003; H. C. Britt et al., 2005; Deveugele et al., 2002) and can be thought as a measure of exogenous practice style (Schurer, Kuehnle, Scott, \& Cheng, 2016).

${ }^{5} \mathrm{~A}$ level B consultation is defined in the Medicare regulations as - Professional attendance involving taking a selective history, examination of the patient with implementation of a management plan in relation to one or more problems OR a professional attendance of less than 20 minutes duration ( $\mathrm{H}$. Britt, Valenti, Miller, \& Farmer, 2004). Level B consultations account for about $80 \%$ of all consultations [(H. Britt et al., 2004) (http://medicarestatistics.humanservices.gov.au/statistics/mbs_group.jsp)]
} 
As shown in the bottom panel of Figure 1, the market clearing condition is that demand for consultations equals the supply of consultations which is inelastic with respect to waiting time, and demand adjusts via waiting time:

$$
D\left(w, q ; x_{d}, \epsilon_{d}\right)-n=0,
$$

Hence the equilibrium waiting time is given by:

$$
w=w\left(q, n^{*} ; x_{d}, \epsilon_{d}\right)=w\left(q, h^{*}\left(m, q ; t, x_{c}, x_{g}, \epsilon_{c}, \epsilon_{g}\right) / t ; x_{d}, \epsilon_{d}\right)
$$

which is decreasing in the supply of GP consultations and increasing in the quality of the GP.

\subsection{Econometric strategy}

We want to estimate the quasi-reduced form (8) for waiting time and assume a linear form for the waiting time for GP $i$ in year $t$ :

$$
W_{i t}=\beta_{0}+\beta_{1} h_{i t}+\beta_{2} X_{i t}+\gamma_{i}+\lambda_{t}+\epsilon_{i t}
$$

where $h_{i t}$ is the average weekly total hours worked by GP $i$ in year $t . \beta_{1}$ is the coefficient of primary interest and is the effect of an hour change in the total hours worked by a GP on the average waiting time to see the GP. To capture the effect of $x_{g}, x_{c}, x_{d}$ and $q$ from our theoretical model we include $X_{i t}$, a vector of observed characteristics of the GP, her practice, and the area where it is located. $X_{i t}$ also includes a measure of consultation length. GP fixed effects $\gamma_{i}$ captures time-invariant unobserved GP characteristics. $\lambda_{t}$ are year fixed effects that control for shocks that affect waiting times for all GPs.

The inclusion of GP fixed effects accounts for time-invariant unobserved heterogeneity that affects both GP's labour supply and waiting time. However, hours worked by GPs may also be correlated with unobserved time-varying confounding factors such as unobserved changes in patient case mix. We therefore instrument hours worked with a set of indicators capturing GP family type. Family circumstances, such as having young dependent children and the working status of the spouse have been shown in previous studies to be strongly correlated with hours worked (Becker, 1985; Bertrand \& Hallock, 2001; Joyce, Wang, \& Cheng, 2015; Schurer et al., 2016). For these family characteristics to be valid instruments, in addition to being correlated 
with the GP's hours worked, they should not impact on the demand for GP consultations and hence waiting times through any mechanism other than the hours worked by GPs.

It is unlikely that family circumstances, such as having a young child and a spouse who works full time, will directly affect demand for consultations with the GP and hence waiting times. However, there might be concern that correlation between waiting times and family characteristics could arise if GPs respond to demand shocks by changing their hours of work and those of their partner. We argue that this unlikely because decisions about labour supply and fertility are typically made in a life-cycle setting and based on lifetime utility (Heckman, 1983; Killingsworth \& Heckman, 1986; MaCurdy, 1981; Montgomery \& Trussell, 1986). For this reason, short term changes in demand for GP services are unlikely to lead to significant changes in spousal labour supply nor are they likely to affect important life-cycle decisions such as having children. ${ }^{6}$ Evidence from studies of physicians and their partners find that life cycle decisions follow the traditional gendered division of labour in the household: priority is often given to the career of the male partner even if both partners have the same level of education (Gjerberg, 2003; Schurer et al., 2016; Stamm \& Buddeberg-Fischer, 2011; Wang \& Sweetman, 2013). Parenthood is associated with a significant reduction in hours of work for female physicians, while for male physicians the effects of marriage and parenthood are much less evident. This is so for physician/non-physician and for physician/physician couples (Stamm \& Buddeberg-Fischer, 2011; Wang \& Sweetman, 2013). Therefore, we argue that our set of indicators measuring family circumstance are reasonably excluded from the waiting time equation as it is unlikely that demand-side shocks will materially affect the family dynamics. ${ }^{7}$

We present results for OLS, OLS with GP fixed effects, IV and fixed effects IV (FEIV) models. We compute robust standard errors clustered on individual GP. IV and FEIV are inefficient in the

\footnotetext{
${ }^{6}$ Appendix Table A3 presents the transition probabilities of GPs moving into different family types. They are broadly in line with traditional life-cycle behaviour. For example: single GPs with no children who change type are most likely to acquire a child and no partner in the next period, and next most likely to acquire a partner and have no dependent children. GPs with a nonworking partner and dependent children are most likely to change type to having dependent children and a partner who works part time.

${ }^{7}$ Notice that in the theoretical model of section 2.2 that neither demand factors nor waiting time to see the GP affect the utility of GPs or their income. Hence, GP hours do not vary with demand shocks. Rather demand shocks lead only to changes in waiting time. In Figure 1, the supply curve of consultations is vertical in $(w, n)$ space. For demand shocks to affect hours worked (and hence waiting times) requires that the GP cares directly about patient waiting times.
} 
presence of heteroscedasticity. As the Pagan and Hall test suggests that heteroscedasticity is present (Baum, Schaffer, \& Stillman, 2007), we estimate our model using the two-step Generalized Method of Moments (GMM) estimator.

\section{Data and descriptive statistics}

\subsection{Data}

The data is from the Medicine in Australia: Balancing Employment and Life (MABEL) survey, an annual prospective cohort study of workforce participation, labour supply and its determinants among Australian doctors. The survey provides exceptionally rich data on doctors' workload, qualifications, practice settings, personal characteristics, geographic location, and family circumstances (Joyce et al., 2010). For the first wave in 2008 , a total of 54,750 doctors (the population of all doctors in Australia) across four broad groups within the medical workforce were invited to participate. The response rate was $19.36 \%$ with a total of 10,498 doctors in the baseline cohort, which includes 3,906 GPs, 4,597 specialists, 1,072 specialists-in-training, and 924 hospital non-specialists. Joyce et al. (2010) found the 2008 cohort to be representative of the overall doctor population with respect to age, gender, geographic location, and hours worked.

In each subsequent wave of MABEL, all doctors who had previously completed a survey plus a cohort of new doctors were invited to participate. Attrition of the 2008 cohort in 2014 is $49.9 \%$. Attrition is higher in subsequent cohorts, between 53-69\%, mainly because these cohorts largely consisted of doctors new to clinical practice who tend to have lower response rates generally and are less likely to participate longitudinally. The MABEL attrition rates are lower than other medical workforce surveys, both nationally and internationally (such as the US Community Tracking Study) (Taylor, Scott, \& Leahy, 2015).

We use data on GPs from the first seven waves of MABEL (2008-2014). The outcome of interest is waiting time for an appointment with the GP, measured in days. ${ }^{8}$ Since we use self-reported data on waiting times, there might be a concern regarding measurement error. We argue that,

\footnotetext{
${ }^{8}$ The outcome variable is based on responses to the survey question - 'Excluding emergencies or urgent needs, for how many days does a patient typically have to wait for you, their preferred doctor in the practice? (Please write average number of days).'
} 
because there are no waiting time targets for primary care physicians in Australia, GPs have no systematic incentives to over-report or under-report their waiting times. Therefore, any measurement error in waiting times is likely to be random, so that estimates will be unbiased and consistent. ${ }^{9}$

We use total hours worked per week as the measure of labour supply. In addition to total hours worked, GPs are asked to report the number of hours worked in different settings and on different activities. ${ }^{10}$ We exclude GP-year observations if the difference between the total number of working hours reported across different settings and the reported weekly total hours worked is 5 or more hours. We then exclude GP-year observations if reported weekly total hours worked are below 4 hours or exceed 75 hours. Finally, we form our baseline estimation sample by excluding GP-year observations if the reported waiting time for an appointment was greater than 30 days. ${ }^{11}$

As instruments for hours worked we use a set of indicator variables for GP's family circumstances based on whether the GP has a partner, the employment status of the partner, the number of children and the age of the youngest child.

The estimation sample is restricted to GPs with non-missing information on all relevant variables and who have at least two observations across the seven waves. The analysis sample size is 14,544 observations on $3,561 \mathrm{GPs}^{12}$

\subsection{Descriptive statistics}

Figure 2 presents the distribution of waiting times and hours worked for the estimation sample. Most GPs have waiting time of less than 5 days and work between 20 to 55 hours a week.

\footnotetext{
${ }^{9}$ For practices with more than one MABEL GP respondent, reports of waiting times "for any doctor in the practice" and "waiting time for a new patient" agreed closely. The Australian Bureau of Statistics Patient Experience Survey asks patients about waiting times but only for urgent appointments (Australian Bureau of Statistics, 2017), so patient reports cannot be compared, even in aggregate, with MABEL GP reports of waiting times "excluding emergencies or urgent needs".

10 The settings in which GPs are asked to report hours worked are - Private medical practitioner's room, community centre/state-run primary care organization, public hospital, private hospital, residential/aged care facility, aboriginal health service, Govt. department/agency/defence forces, tertiary education institution, and other. The activities on which GPs are asked to report hours worked are - Direct patient care, indirect patient care, education activities, management and administration, and other.

${ }^{11}$ The distribution plots of waiting time in our data (see Figure 2) show that for most GPs the waiting times are well under 30 days. We tested the sensitivity of the results to the waiting time cut offs defining the sample (see Appendix Table A6).

${ }^{12}$ Appendix Table A1 shows the number of observations that were lost for different reasons.
} 
Table I presents the descriptive statistics for the estimation sample. The average waiting time for a GP is 4.02 days and the average total hours worked per week is 37.54 . Half of the GPs in the estimation sample are women. The majority of GPs are Australian medical graduates (74\%), their average length of a standard (level B) consultation is 15.82 minutes, and they bulk-bill 61 percent of their patients. ${ }^{13}$ Most GPs are salaried or contracted employees (57\%) and practice in cities (67\%). Around 11 percent of GPs have dependent children aged under 5 years, and 50 percent have a partner who is either not working or working part-time.

The last two columns of Table I show that although the variation between different GPs is larger than variation within GPs (over time), there is still considerable within variation for waiting time and total hours worked to support fixed-effects analysis. There is little variation, between or within GPs, in the consultation length with the average varying less than 4 minutes between GPs and less than 2 minutes for a GP over time. This indicates that most GPs have a standard consultation between 15-20 minutes, supporting our assumption of exogeneity of consultation length.

There is nontrivial within-variation in the family characteristics we use as instruments. Appendix Table A3 reports GP transition probabilities between different family types. Each year, about 17 percent of single GPs in the data become partnered. From one year to the next, about 20 percent of GPs with a partner who is either not working or working part-time and who have a dependent child aged under 5 see their child turn 5 and age out of this category. Further, for a sizeable proportion of GPs, the partner's work-status changes from not working to working part-time, or from working part-time to either not working or working full-time from one year to the next.

[Figure 2 here]

[Table I here]

The estimation sample has broadly similar characteristics to the GP population (Australian Institute of Health and Welfare, 2015) except that it has a larger proportion of female GPs (50\%

\footnotetext{
${ }^{13}$ The MABEL survey asks GPs to report the proportion of patients bulk-billed, while the figure of over $80 \%$ bulk-billing reported by Department of Health (Department of Health, 2017) is based on the proportion of GP services (not patients) bulk-billed.
} 
against $40 \%$ in the GP population) which may account for the average total hours worked per week being lower than the population average (37.54 against 42.7 hours in the population over 2008-2014)..$^{14}$

\section{Regression results}

Table IIA presents results from estimating equation (9). We focus on reporting estimates of the coefficient of interest $\beta_{1}$, the impact of hours worked on waiting time. The OLS estimate (column 1) has a positive and statistically significant coefficient on total hours worked, implying that a decrease in hours worked by a GP is associated with lower waiting times. However, once we control for GP fixed effects (column 2), the coefficient becomes statistically insignificant. ${ }^{15}$

Columns 3 and 4 of Table IIA present the results from IV and FEIV estimation. The C or GMM distance test of endogeneity confirmed the endogeneity of total hours worked in both IV and FEIV models, with the null of exogeneity rejected at $1 \%$ level of significance. The IV model (column 3) exploits the between-GP variation and has a coefficient of -0.066 on total hours worked, suggesting that a one hour decrease in average total hours worked per week is associated with a rise in average waiting time of 0.066 days, which is a $1.64 \%$ increase relative to the mean waiting time (4.02 days). This estimate implies that a $10 \%$ (or 3.75 hours) reduction in hours worked would increase the average waiting time by $6.2 \%$. The FEIV model (column 4 ) is our preferred model since it additionally exploits within-GP variation. The estimated coefficient of -0.125 on total hours worked implies that a $10 \%$ reduction in average total hours worked per week would increase the average waiting time by $11.7 \%{ }^{16}$

The instruments are stronger in the IV model (excluded instruments F statistic $=41.09$ $(p<0.000)$, partial $R^{2}=0.048$ in column 3 Table IIA) than in the FEIV model (excluded instruments $F$ statistic $=17.16(p<0.000)$, partial $R^{2}=0.018$ in column 4 Table IIA) because

\footnotetext{
${ }^{14}$ Table A2 in the appendix presents the descriptive statistics separately for female and male GPs.

${ }^{15}$ Means of GP time varying variables added to a random effects specification were jointly significant at $1 \%$, suggesting that fixed effects is the appropriate specification (Wooldridge, 2010).

${ }^{16}$ We also estimated models varying the waiting time cut offs used to define the sample by (i) dropping the top and bottom $1 \%$ (ii) dropping observations with waiting times over 25 days (rather than 30), (iii) dropping observations with waiting times over 15 days. The results (Appendix Table A6) are qualitatively similar to the baseline model (hours worked remain highly statistically significant and the instruments strong), though the effect of hours worked is reduced by about two fifths in the sample with the tightest (15 days) waiting time cut off.
} 
overall variation is greater than within GP variation in the data. ${ }^{17}$ Both IV and FEIV models pass the under-identification test. Table IIB presents the results for the first stage total hours worked regression. As expected, having dependent children aged under 5 years is associated with a significant reduction in total hours worked, and this negative effect is greater for those whose partner works full time.

The effect of GP, practice and area characteristics are consistent across the models. GPs who spend more time per patient, who graduated from an Australian medical school or have a postgraduate qualification or Fellowship of a college, have higher waiting times. This suggests that patients associate these characteristics with higher quality. Tenure in practice is also found to be positively associated with waiting times, with waiting times increasing with tenure but at a decreasing rate suggesting that patients prefer to consult GPs who have been in the practice for longer.

GPs who are employees (contracted/salaried or working as locum) have lower waiting times compared to GPs who are principals or partners in the practice. The coefficient on the number of nurses is positive and significant, suggesting that practices with high waiting times might be employing more nurses. ${ }^{18}$ Regional and remote areas have higher waiting times compared to major cities. GPs in higher socio-economic areas have lower waiting times which is consistent with the waiting time literature (Cooper, McGuire, Jones, \& Le Grand, 2009; Laudicella, Siciliani, \& Cookson, 2012; Roll et al., 2012; Sharma, Siciliani, \& Harris, 2013; Siciliani \& Verzulli, 2009; Sudano \& Baker, 2006).

GPs located closer to emergency departments have higher waiting times. This seems counterintuitive since a proportion of emergency department patients have non-urgent conditions which could be dealt with by a GP. A possible explanation is that emergency departments are using triage systems where patients who are classified as 'non-urgent' are re-directed from the ED to co-located primary care services (Carson, Clay, \& Stern, 2010; Government of Western

\footnotetext{
${ }^{17}$ Table A3 in the appendix shows the within-variation in instruments, presenting the transition probabilities of GPs moving into different family types or characteristics (i.e. our 9 instrument dummy variables) each year.

${ }^{18}$ This suggests that number of nurses are endogenous. As a robustness check we estimated models excluding number of nurses as a covariate, and the point estimates of the effect of hours worked on waiting times for all models were almost unchanged.
} 
Australia, 2004). This might lead to increases in workload and waiting times at the co-located primary care practices, especially as there is no patient registration with GP practices in Australia, so that patients turned away from ED can go to the closest practice. ${ }^{19}$

[Table IIA and IIB here]

\subsection{Alternative measures of labour supply}

We estimated models with two alternative measures of GP labour supply. First, we use hours worked in direct patient care as the measure of labour supply. Second, to investigate the sensitivity of results to the specification of consultation length, we estimate models using the number of patients (visits) seen per week rather than hours worked. ${ }^{20}$

Table III presents the results from IV and FEIV model. The baseline results (using total hours worked per week as the measure of labour supply) are repeated in panel $C$. The results using hours worked in direct patient care (panel A) are qualitatively similar to the baseline results, however, the magnitude of the effect is slightly higher, possibly because the explanatory variable has a slightly smaller scale. The instruments are relatively weaker for direct patient hours, particularly in FEIV model (panel A, column 2) perhaps because hours spent in direct patient care might be affected by other factors in the practice as well as by family circumstances. $^{21}$

The number of patients (visits) seen per week is negatively and significantly associated with waiting times for the IV model (panel B, column 1). The estimate from the IV model suggests that if a GP sees one patient less a week, the average waiting time would increase by 13 minutes, slightly less than the average length of a consultation. The instruments are weak for the FEIV model $(F=6.428)$ possibly due to smaller within-GP variation in the number of patients seen (within-GP variation is just 23 patients compared to between-GP variation of around 53 patients).

\footnotetext{
${ }^{19}$ As a robustness check, we estimated the baseline models excluding the minimum distance to ED variable from the analysis and found the estimates were almost unchanged.

${ }^{20}$ We could not find any instrument for consultation length $(t)$ and hence could not formally test for endogeneity of $t$.

${ }^{21}$ Both C or GMM distance test and Durbin-Wu-Hausman test indicated that hours worked in direct patient care are endogenous at $5 \%$ level.
} 
[Table III here]

\subsection{Bulk billing}

In our theoretical model, we assumed that GPs bulk-bill all patients. We examine the sensitivity of our results to the extent of bulk-billing by estimating models separately for the sample of GPs who bulk-bill $80 \%$ or more of their patients and those who bulk-bill less than $80 \%$ of their patients. ${ }^{22}$ The results are reported in panel A of Table IV. For GPs bulk-billing $80 \%$ or more of their patients, we still find a negative and statistically significant relationship between total hours worked and waiting times for the IV model (panel A, column 1), and the magnitude is somewhat larger than in the baseline IV results (panel D, column 1). In the FEIV model, the instruments are weak and estimates are imprecise perhaps because the number of GPs in the sub-sample is small. For GPs bulk-billing less than $80 \%$ percent of their patients we find a negative and statistically significant effect of total hours worked on waiting times for the FEIV model which is similar to that in the baseline model. As a further robustness check, we also estimated the baseline model for the full sample but excluding the bulk-billing variable from the analysis and found that results were almost unchanged (see Table A5 in the appendix).

\subsection{Female and male GPs}

Female GPs work fewer hours on average (31.64 hours) than male GPs (43.35 hours) and have higher average waiting times (4.28 days against 3.76 days for male GPs). Table A2 in the appendix presents the descriptive statistics by gender. It shows that female and male GPs are also different in several other characteristics controlled for in our baseline analysis. Estimating models separately for female and male GPs allows analysis on a more homogenous sample of GPs who are more likely to be similar in their unobservable characteristics which might affect demand for consultations and waiting times.

Table IV panel B presents the results for female and male GPs. The coefficient on total hours worked is negative in both IV and FEIV models for both female and male GPs. For female GPs, the IV model has negative but statistically insignificant coefficient on total hours worked (-

\footnotetext{
${ }^{22}$ We did not restrict the sample to GPs who bulk-bill $100 \%$ percent of their patients due to very small sample size to perform the analysis.
} 
0.042), while the FEIV model has significantly negative but smaller in magnitude (compared to baseline result) coefficient on total hours worked. For male GPs, the instruments are weak in both IV and FEIV models and hence the estimates are likely to be biased.

Table A4 in the appendix reports the separate first stage results for female and male GPs. Compared to the first stage results for all GPs (Table IIB), the F-Statistics on the excluded IVs for female GP labour supply is similar to the baseline models but considerably smaller for male GPs. For female GPs, both young dependent children and working status of the spouse are associated with labour supply decisions. For example, having dependent children aged under 5 years and a partner who works full time is associated with a reduction in total hours worked per week of about 13 hours as compared to a single female GP without young dependent children. The instruments work well for female GPs.

We find that employment status of the spouse plays a negligible role in the labour supply decisions of male GPs and their labour supply response to having children is also weak. ${ }^{23}$ However, there is a significant negative association between male GP hours and having dependent children aged under 5 years and a partner who works full time compared to a single male GP without young dependent children. Although the family circumstance instruments might be working for some male GPs in the sample, overall the instruments are weak for male GPs hours and hence estimates are likely to be biased. ${ }^{24}$

\subsection{Employee vs self-employed GPs}

Next, we examine whether the results are driven by GPs who are principals/partners or associates in the practice and who therefore have greater control over working hours. The results from separate models for GPs who are employees and for principal/partner GPs are in table IV panel C. Overall, the results are qualitatively similar to the baseline results. For employee GPs, we still find a negative and statistically significant effect of hours worked on waiting times for both IV and FEIV models, although the magnitude of the effect is slightly

\footnotetext{
${ }^{23}$ A recent study on Australian GPs also found that male GPs do not significantly alter their labour supply in response to having children (Schurer et al., 2016)

${ }^{24}$ We were unable to find any other instruments for male GP hours and so could not further test for and correct endogeneity of male GP hours.
} 
smaller compared to the baseline results. Due to the small sample size of self-employed GPs, the instruments are weak and the estimates of the effects of hours worked are imprecise.

\section{[Table IV here]}

\section{Conclusion}

This study is the first to examine the extent to which the labour supply of GPs at the intensive margin affects access to primary care, as measured by waiting times. Our analysis takes into account both time-invariant and time-varying unobserved confounding factors potentially correlated with both hours worked by GPs and their waiting times. Controlling for demand-side factors, we find that a $10 \%$ reduction in the average hours worked by a GP would increase the average time a patient waits to see the GP by $12 \%$.

Our results have implications for policy to improve access to primary care. They suggest that the current trend of declining working hours of GPs, primarily driven by increasing feminisation of medical workforce and a shift in preference for working predictable and fewer hours, is likely to lead to longer waiting times for patients.

In several OECD countries, policymakers have focussed on encouraging general practices to provide extended working hours in an attempt to improve access. For example, in the U.K., the government launched seven day opening of GP practices in 2013 (Dolton \& Pathania, 2016), and in Australia, the government provides financial incentives for GPs to offer additional afterhours coverage to patients (Department of Human Services, 2015b). However, evidence from stated preference studies suggests that financial incentives will have little impact on increasing the total hours worked by GPs (Broadway, Kalb, Li, \& Scott, 2017; Kalb, Kuehnle, Scott, Cheng, \& Jeon, 2015). And in the absence of an increase in the number of GPs, reallocating the supply of their hours worked across the week could increase waiting times during normal weekday GP office hours.

This suggests that policies which operate on the extensive margin will be required. Many countries, including Australia, have recruited medical graduates from overseas to increase GP supply in the short-term (WHO, 2010). In the long-term countries often use a mix of 
immigration and other policies aimed at improving retention and increasing domestic training, to address structural imbalances between supply and demand (OECD, 2008, 2016).

A third possibility is to improve access to primary care by changing the mix of primary care health workers. Some studies suggest that primary care capacity could be increased by shifting care from doctors to nurses (Bodenheimer \& Smith, 2013; Ghorob \& Bodenheimer, 2012). However, high-quality evaluations of the impact of nurses on primary care capacity and access to primary care services are still scarce (Laurant et al., 2005).

Finally, a further policy response to increase GP labour supply could be to improve childcare options available to them. As demonstrated by the results for our first stage labour supply models and corroborated by evidence from several OECD countries, child-bearing reduces female doctors' labour supply (British Medical Association, 2015; Cleland, Johnston, Anthony, Khan, \& Scott, 2014; Wang \& Sweetman, 2013). It is currently unclear the extent to which access to childcare impacts the labour supply decisions of female doctors, but this would appear to be an important avenue for further research.

This article is protected by copyright. All rights reserved. 


\section{References}

Australian Bureau of Statistics. (2017). Patient Experiences in Australia: 2016-17. Retrieved from http://www.abs.gov.au/ausstats/abs@.nsf/Lookup/by\%20Subject/4839.0 201617 Main\%20Features General\%20practitioners 2

Australian Institute of Health and Welfare. (2015). Medical Practitioner workforce. . Retrieved from http://www.aihw.gov.au/workforce/medical/

Baum, C. F., Schaffer, M. E., \& Stillman, S. (2007). Enhanced routines for instrumental variables/GMM estimation and testing. Stata Journal, 7(4), 465-506.

Becker, G. S. (1985). Human capital, effort, and the sexual division of labor. Journal of labor economics, S33-S58.

Bensing, J. M., Roter, D. L., \& Hulsman, R. L. (2003). Communication patterns of primary care physicians in the United States and the Netherlands. Journal of general internal medicine, 18(5), 335-342.

Bertrand, M., \& Hallock, K. F. (2001). The gender gap in top corporate jobs. Industrial \& Labor Relations Review, 55(1), 3-21.

Bindman, A. B., Grumbach, K., Osmond, D., Komaromy, M., Vranizan, K., Lurie, N., . . Stewart, A. (1995). Preventable hospitalizations and access to health care. Jama, 274(4), 305-311.

Bodenheimer, T. S., \& Smith, M. D. (2013). Primary care: proposed solutions to the physician shortage without training more physicians. Health Affairs, 32(11), 1881-1886.

British Medical Association. (2015). 2014 UK Medical Workforce - Briefing. Retrieved from https://www.bma.org.uk/Lmedia/files/pdfs/working\%20for\%20change/policy\%20and\%20lobbying/uk\%20medical\%20wor kforce\%20briefing\%20may\%202015\%20final.pdf

Britt, H., Miller, G. C., Henderson, J., Bayram, C., Harrison, C., Valenti, L., . . Gordon, J. (2016). General practice activity in Australia 2015-16. General practice series no. 40. Sydney: Sydney University Press 2016.

Britt, H., Miller, G. C., Henderson, J., Bayram, C., Valenti, L., Harrison, C., . . Pollack, A. (2013). A decade of Australian general practice activity 2003-04 to 2012-13: General practice series no. 34 (Vol. 34): Sydney University Press.

Britt, H., Valenti, L., Miller, G. C., \& Farmer, J. (2004). Determinants of GP billing in Australia: content and time. Medical Journal of Australia, 181, 100-105.

Britt, H. C., Valenti, L., \& Miller, G. C. (2005). Determinants of consultation length in Australian general practice. Medical Journal of Australia, 183(2), 68.

Broadway, B., Kalb, G., Li, J., \& Scott, A. (2017). Do Financial Incentives Influence GPs' Decisions to Do After-hours Work? A Discrete Choice Labour Supply Model. Health economics. doi:10.1002/hec.3476

Carson, D., Clay, H., \& Stern, R. (2010). Primary Care and Emergency Departments. Primary Care Foundation. Retrieved from U.K. Department of Health: https://www.primarycarefoundation.co.uk/images/PrimaryCareFoundation/Downloading Repo rts/Reports and Articles/Primary Care and Emergency Departments/Primary Care and Eme rgency Departments RELEASE.pdf

Cheraghi-Sohi, S., Hole, A. R., Mead, N., McDonald, R., Whalley, D., Bower, P., \& Roland, M. (2008). What patients want from primary care consultations: a discrete choice experiment to identify patients' priorities. The Annals of Family Medicine, 6(2), 107-115.

Cleland, J. A., Johnston, P. W., Anthony, M., Khan, N., \& Scott, N. W. (2014). A survey of factors influencing career preference in new-entrant and exiting medical students from four UK medical schools. BMC Medical Education, 14(1), 1-10. doi:10.1186/1472-6920-14-151

This article is protected by copyright. All rights reserved. 
Cooper, Z. N., McGuire, A., Jones, S., \& Le Grand, J. (2009). Equity, waiting times, and NHS reforms: retrospective study. $B M J, 339$.

Cowling, T. E., Cecil, E. V., Soljak, M. A., Lee, J. T., Millett, C., Majeed, A., . . Harris, M. J. (2013). Access to primary care and visits to emergency departments in England: a cross-sectional, populationbased study. PloS one, 8(6), e66699.

Crossley, T. F., Hurley, J., \& Jeon, S. H. (2009). Physician labour supply in Canada: a cohort analysis. Health economics, 18(4), 437-456.

Cullis, J. G., \& Jones, P. R. (1986). Rationing by waiting lists: an implication. The American economic review, 76(1), 250-256.

Department of Health. (2017). Quarterly Public Release of Medicare Statistics: 2016-17 Financial Yearto-Date Bulk Billing Rates. Retrieved from http://www.health.gov.au/internet/main/publishing.nsf/Content/Quarterly-Medicare-Statistics

Department of Human Services. (2015a). Incentive payments to GPs who bulk bill concessional patients and children aged under 16 years. . Retrieved from https://www.medicareaustralia.gov.au/provider/incentives/files/incentive payments to GPs who bulk bill concessional patients under 16.pdf

Department of Human Services. (2015b). Practice Incentive Program - After hours Incentive

Retrieved from http://www.humanservices.gov.au/health-professionals/services/practice-incentivesprogramme/pip-after-hours-incentive

Department of Human Services. (2016). Claiming bulk bill incentives. Retrieved from https://www.humanservices.gov.au/health-professionals/enablers/education-guide-claimingbulk-bill-incentive-items

Deveugele, M., Derese, A., van den Brink-Muinen, A., Bensing, J., \& De Maeseneer, J. (2002). Consultation length in general practice: cross sectional study in six European countries. BMJ, 325(7362), 472.

Dolton, P., \& Pathania, V. (2016). Can increased primary care access reduce demand for emergency care? Evidence from England's 7-day GP opening. Journal of health economics, 49, 193-208.

Gandhi, I., Parle, J., Greenfield, S., \& Gould, S. (1997). A qualitative investigation into why patients change their GPs. Family practice, 14(1), 49-57.

Gerard, K., Salisbury, C., Street, D., Pope, C., \& Baxter, H. (2008). Is fast access to general practice all that should matter? A discrete choice experiment of patients' preferences. Journal of Health Services Research \& Policy, 13(suppl 2), 3-10.

Ghorob, A., \& Bodenheimer, T. (2012). Sharing the care to improve access to primary care. New England Journal of Medicine, 366(21), 1955-1957.

Gjerberg, E. (2003). Women doctors in Norway: the challenging balance between career and family life. Social science \& medicine, 57(7), 1327-1341.

Goddard, J., Malek, M., \& Tavakoli, M. (1995). An economic model of the market for hospital treatment for non-urgent conditions. Health economics, 4(1), 41-55.

Government of Western Australia. (2004). New medical centres to ease pressure on emergency departments. Media statements. [Press release]. Retrieved from https://www.mediastatements.wa.gov.au/Pages/Gallop/2004/04/New-medical-centres-toease-pressure-on-emergency-departments.aspx

Gravelle, H., Scott, A., Sivey, P., \& Yong, J. (2016). Competition, prices and quality in the market for physician consultations. The Journal of Industrial Economics, 64(1), 135-169.

Gravelle, H., Smith, P., \& Xavier, A. (2003). Performance signals in the public sector: the case of health care. Oxford Economic Papers, 55(1), 81-103. 
Heckman, J. (1983). A life-cycle model of family labour supply Human resources, employment and development (pp. 213-230): Springer.

Iversen, T. (1993). A theory of hospital waiting lists. Journal of health economics, 12(1), 55-71.

Joyce, C. M., McNeil, J. J., \& Stoelwinder, J. U. (2006). More doctors, but not enough: Australian medical workforce supply 2001-2012. Medical Journal of Australia, 184(9), 441.

Joyce, C. M., Scott, A., Jeon, S.-H., Humphreys, J., Kalb, G., Witt, J., \& Leahy, A. (2010). The "Medicine in Australia: Balancing Employment and Life (MABEL)" longitudinal survey-Protocol and baseline data for a prospective cohort study of Australian doctors' workforce participation. BMC Health Services Research, 10(50), 1-10.

Joyce, C. M., Wang, W. C., \& Cheng, T. C. (2015). Changes in Doctors' Working Hours A Longitudinal Analysis. Medical Care Research and Review, 1077558715589705.

Kalb, G. R., Kuehnle, D., Scott, A., Cheng, T. C., \& Jeon, S.-H. (2015). What Factors Affect Doctors' Hours Decisions: Comparing Structural Discrete Choice and Reduced-Form Approaches. MELBOURNE INSTITUTE WORKING PAPER NO. 10/15.

Killingsworth, M. R., \& Heckman, J. J. (1986). Chapter 2 Female labor supply: A survey Handbook of labor economics (Vol. 1, pp. 103-204): Elsevier.

Kirch, D. G., \& Vernon, D. J. (2008). Confronting the complexity of the physician workforce equation. Jama, 299(22), 2680-2682. doi:10.1001/jama.299.22.2680

Kontopantelis, E., Roland, M., \& Reeves, D. (2010). Patient experience of access to primary care: identification of predictors in a national patient survey. BMC Family Practice, 11(1), 61.

Laudicella, M., Siciliani, L., \& Cookson, R. (2012). Waiting times and socioeconomic status: evidence from England. Social science \& medicine, 74(9), 1331-1341.

Laurant, M., Reeves, D., Hermens, R., Braspenning, J., Grol, R., \& Sibbald, B. (2005). Substitution of doctors by nurses in primary care. Cochrane Database Syst Rev, 2(2).

Lindsay, C. M., \& Feigenbaum, B. (1984). Rationing by waiting lists. The American economic review, 404417.

MaCurdy, T. E. (1981). An empirical model of labor supply in a life-cycle setting. Journal of Political Economy, 89(6), 1059-1085.

Martin, S., Jacobs, R., Rice, N., \& Smith, P. (2003). Waiting times for elective surgery: A hospital based approach. Report, University of York, York.

Martin, S., \& Smith, P. C. (1999). Rationing by waiting lists: an empirical investigation. Journal of Public Economics, 71(1), 141-164.

Montgomery, M., \& Trussell, J. (1986). Models of marital status and childbearing. Handbook of labor economics, 1, 205-271.

Muggah, E., Hogg, W., Dahrouge, S., Russell, G., Kristjansson, E., Muldoon, L., \& Devlin, R. A. (2014). Patient-reported access to primary care in Ontario Effect of organizational characteristics. Canadian Family Physician, 60(1), e24-e31.

OECD. (2008). OECD Health Policy Studies. The Looming Crisis In the Health Workforce: How Can OECD Countries Respond? Retrieved from http://www.who.int/hrh/migration/looming crisis health workforce.pdf

OECD. (2016). Health Workforce Policies in OECD Countries: Right Jobs, Right Skills, Right Places. Retrieved from https://www.oecd.org/health/health-systems/Health-workforce-policies-inoecd-countries-Policy-brief.pdf

Roll, K., Stargardt, T., \& Schreyögg, J. (2012). Effect of type of insurance and income on waiting time for outpatient care. The Geneva Papers on Risk and Insurance-Issues and Practice, 37(4), 609-632.

Sarma, S., Thind, A., \& Chu, M.-K. (2011). Do new cohorts of family physicians work less compared to their older predecessors? The evidence from Canada. Social science \& medicine, 72(12), 20492058. 
Sayer, G. P., Britt, H., Horn, F., Bhasale, A., McGeechan, K., Charles, J., . . Scahill, S. (2000). Measures of health and health care delivery in general practice in Australia. General Practice Series 3. Cat. no. GEP 3. Canberra: AlHW

Schurer, S., Kuehnle, D., Scott, A., \& Cheng, T. C. (2016). A Man's Blessing or a Woman's Curse? The Family Earnings Gap of Doctors. Industrial Relations: A Journal of Economy and Society, 55(3), 385-414.

Scott, A. (2000). Economics of general practice. Handbook of health economics, 1, 1175-1200.

Scott, A., \& Vick, S. (1999). Patients, Doctors and Contracts: An Application of Principal-Agent Theory to the Doctor-Patient Relationship. Scottish journal of political economy, 46(2), 111-134.

Scott, A., Watson, M. S., \& Ross, S. (2003). Eliciting preferences of the community for out of hours care provided by general practitioners: a stated preference discrete choice experiment. Social science \& medicine, 56(4), 803-814.

Sharma, A., Siciliani, L., \& Harris, A. (2013). Waiting times and socioeconomic status: Does sample selection matter? Economic Modelling, 33, 659-667.

Shrestha, D., \& Joyce, C. M. (2011). Aspects of work-life balance of Australian general practitioners: determinants and possible consequences. Australian journal of primary health, 17(1), 40-47.

Siciliani, L., Borowitz, M., \& Moran, V. (2013). Waiting Time Policies in the Health Sector: What Works? : OECD Publishing.

Siciliani, L., \& Hurst, J. (2003). Explaining waiting times variations for elective surgery across OECD countries. OECD Health Working Papers, No. 7. doi: http://dx.doi.org/10.1787/406746186162

Siciliani, L., \& Verzulli, R. (2009). Waiting times and socioeconomic status among elderly Europeans: evidence from SHARE. Health economics, 18(11), 1295-1306.

Stamm, M., \& Buddeberg-Fischer, B. (2011). How do physicians and their partners coordinate their careers and private lives. Swiss Med Wkly, 141, w13179.

Sudano, J. J., \& Baker, D. W. (2006). Explaining US racial/ethnic disparities in health declines and mortality in late middle age: the roles of socioeconomic status, health behaviors, and health insurance. Social science \& medicine, 62(4), 909-922.

Taylor, T., Scott, A., \& Leahy, A. (2015). MABEL User Manual: Wave 7 Release. Melbourne Institute of Applied Economic and Social Research, University of Melbourne, Melbourne.

Turner, D., Tarrant, C., Windridge, K., Bryan, S., Boulton, M., Freeman, G., \& Baker, R. (2007). Do patients value continuity of care in general practice? An investigation using stated preference discrete choice experiments. Journal of Health Services Research \& Policy, 12(3), 132-137.

Wang, C., \& Sweetman, A. (2013). Gender, family status and physician labour supply. Social science \& medicine, 94, 17-25.

WHO. (2010). International migration of healthworkers IMPROVING INTERNATIONAL CO-OPERATION TO ADDRESS THE GLOBAL HEALTH WORKFORCE CRISIS. Retrieved from http://www.who.int/hrh/resources/oecd-who policy brief en.pdf

Wooldridge, J. M. (2010). Econometric analysis of cross section and panel data.

Young, A. F., Dobson, A. J., \& Byles, J. E. (2000). Access and equity in the provision of general practitioner services for women in Australia. Australian and New Zealand Journal of Public Health, 24(5), 474-480. 
Figure 1: Determination of waiting times in market for GP consultations

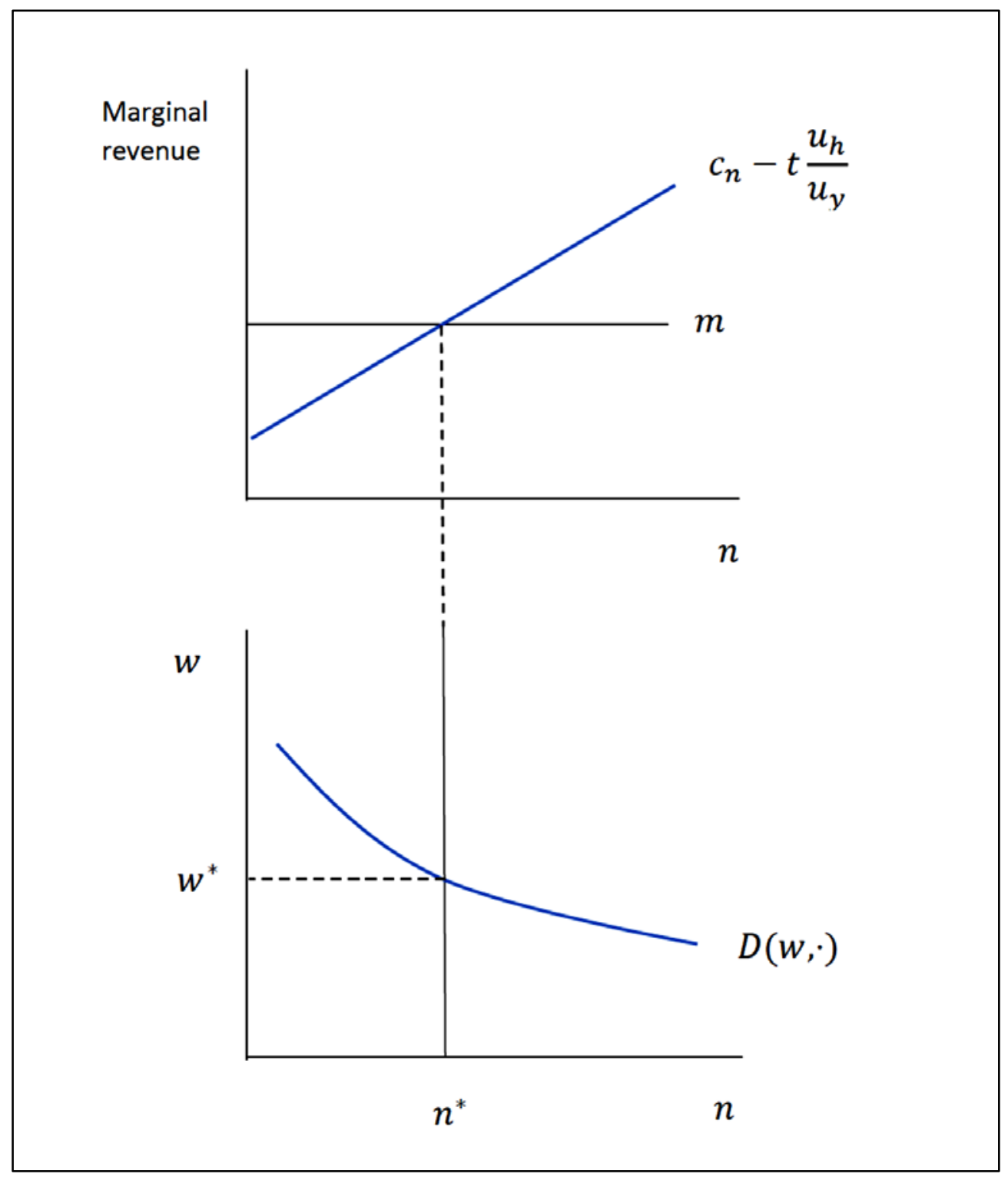

Note. w: waiting time for consultation, $n$ : number of consultations, $m$ : Medicare rebate, $c_{n}$ : marginal cost of consultation, $t$ : length of consultation, $-\mathrm{u}_{\mathrm{h}} / \mathrm{u}_{\mathrm{y}}$ : marginal rate of substitution of hours worked for income (marginal compensation required for an hour work), $\mathrm{D}(\mathrm{w}, \cdot)$ : demand for consultations. Top panel: hours worked determined by full marginal cost $-t\left(u_{h} / u_{y}\right)$ of a consultation and marginal revenue. Bottom panel: waiting time determined by demand and inelastic supply of consultations. 
Figure 2: Distribution of hours worked and waiting times for GPs

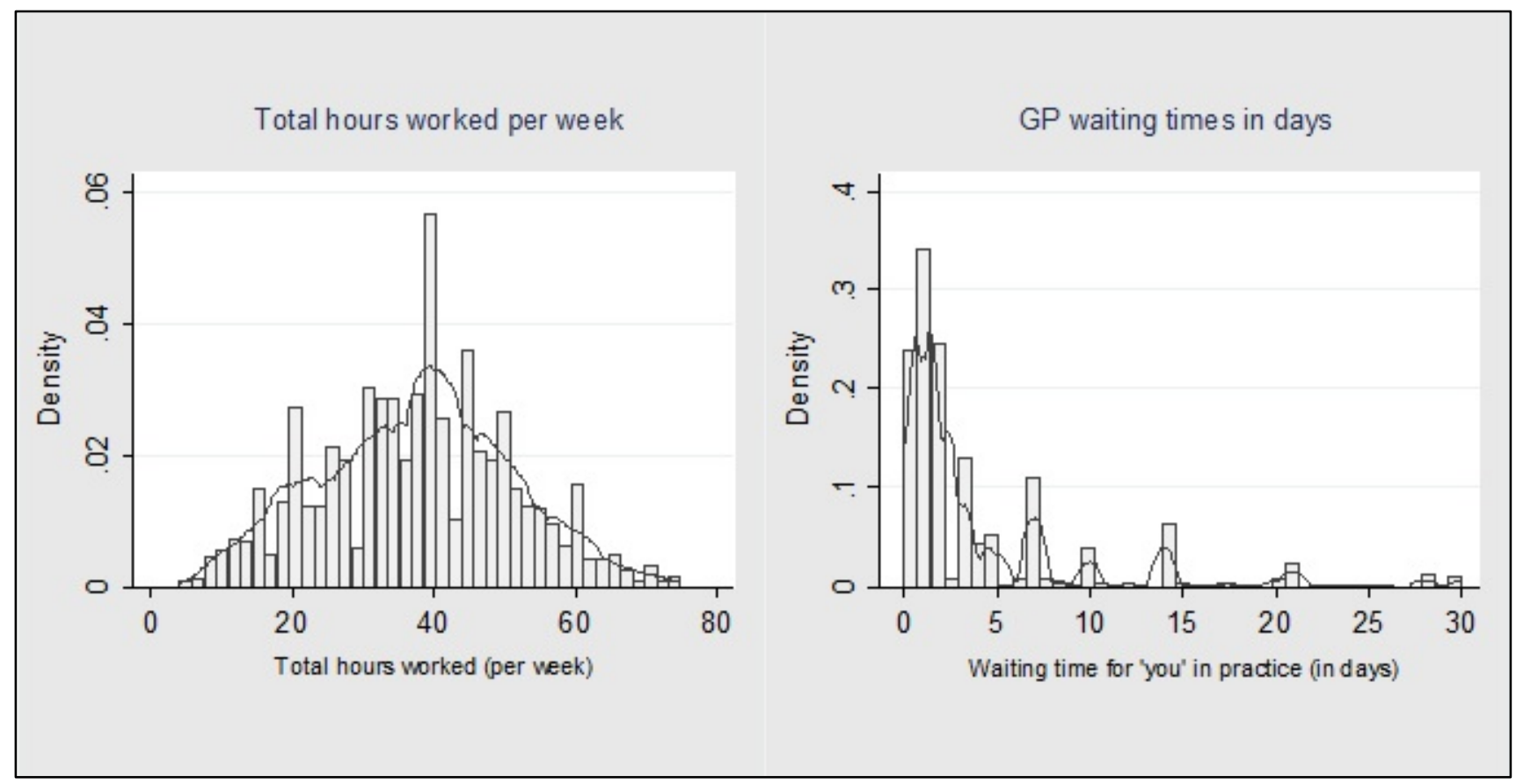

This article is protected by copyright. All rights reserved. 
Table I: Descriptive statistics for estimation sample, pooled across years (2008-2014)

\begin{tabular}{|c|c|c|c|c|c|c|}
\hline \multirow[b]{2}{*}{ Variables } & \multicolumn{4}{|c|}{ Overall } & \multirow{2}{*}{$\begin{array}{c}\text { S D } \\
\text { Between }\end{array}$} & \multirow{2}{*}{$\begin{array}{c}\text { S D } \\
\text { Within }\end{array}$} \\
\hline & Mean & S D & Min & Max & & \\
\hline Waiting time for you in practice & 4.02 & 5.60 & 0 & 30 & 4.99 & 2.72 \\
\hline Total hours worked per week & 37.54 & 13.60 & 4 & 75 & 12.53 & 5.26 \\
\hline Hours worked in direct patient care per week & 31.18 & 12.18 & 4 & 75 & 11.24 & 4.93 \\
\hline No. of patients (visits) seen per week & 110.50 & 57.02 & 10 & 300 & 52.74 & 23.01 \\
\hline \multicolumn{7}{|l|}{ Personal characteristics } \\
\hline Female & 0.50 & 0.50 & 0 & 1 & 0.50 & 0.00 \\
\hline Age: Under 35 & 0.09 & 0.28 & 0 & 1 & 0.30 & 0.12 \\
\hline Age: $35-39$ & 0.11 & 0.31 & 0 & 1 & 0.27 & 0.18 \\
\hline Age: $40-44$ & 0.12 & 0.33 & 0 & 1 & 0.26 & 0.21 \\
\hline Age: $45-49$ & 0.16 & 0.36 & 0 & 1 & 0.28 & 0.24 \\
\hline Age: $50-54$ & 0.18 & 0.38 & 0 & 1 & 0.29 & 0.26 \\
\hline Age: $55-59$ & 0.16 & 0.36 & 0 & 1 & 0.27 & 0.24 \\
\hline Age: $60-64$ & 0.10 & 0.30 & 0 & 1 & 0.23 & 0.20 \\
\hline Age: 65 or over & 0.09 & 0.29 & 0 & 1 & 0.27 & 0.12 \\
\hline Length of std. private consultation & 15.82 & 3.99 & 5 & 30 & 3.61 & 1.88 \\
\hline Australian medical graduate & 0.74 & 0.44 & 0 & 1 & 0.45 & 0.00 \\
\hline Post graduate qualification/Fellowship & 0.61 & 0.49 & 0 & 1 & 0.46 & 0.16 \\
\hline \multicolumn{7}{|l|}{ Practice characteristics } \\
\hline Tenure in practice (years) & 9.00 & 9.81 & 0 & 61 & 9.16 & 3.21 \\
\hline Total no. of GPs in the practice & 7.76 & 4.17 & 1 & 25 & 3.82 & 1.92 \\
\hline$\%$ of patients bulk-billed & 60.56 & 30.15 & 0 & 100 & 27.78 & 12.29 \\
\hline No. of nurses in the practice & 2.39 & 1.90 & 0 & 10 & 1.70 & 0.92 \\
\hline $\begin{array}{l}\text { No. of allied health prof. } \backslash \& \text { administrative staff in } \\
\text { practice }\end{array}$ & 6.18 & 4.20 & 0 & 30 & 3.59 & 2.38 \\
\hline Employment type: Principal or partner & 0.28 & 0.45 & 0 & 1 & 0.41 & 0.18 \\
\hline Employment type: Associate & 0.11 & 0.31 & 0 & 1 & 0.24 & 0.19 \\
\hline Employment type: Salaried or Contracted employee & 0.57 & 0.50 & 0 & 1 & 0.44 & 0.23 \\
\hline Employment type: Locum or other & 0.04 & 0.20 & 0 & 1 & 0.15 & 0.13 \\
\hline \multicolumn{7}{|l|}{ Area characteristics } \\
\hline Location (ASGC): City & 0.67 & 0.47 & 0 & 1 & 0.46 & 0.13 \\
\hline Location (ASGC): Regional & 0.31 & 0.46 & 0 & 1 & 0.45 & 0.13 \\
\hline Location (ASGC): Remote & 0.03 & 0.17 & 0 & 1 & 0.16 & 0.05 \\
\hline SEIFA Index & 1016 & 74.44 & 669.50 & 1213.92 & 70.92 & 23.26 \\
\hline Percent of population under 5 yrs of age & 6.03 & 1.40 & 0.43 & 13.34 & 1.32 & 0.52 \\
\hline Percent of population above 65 yrs of age & 13.89 & 4.96 & 0.18 & 43.37 & 4.71 & 1.67 \\
\hline Min. distance to emergency department & 4.62 & 3.53 & 1 & 19 & 3.29 & 1.29 \\
\hline Ratio of GPs to population (per 1,000 ) & 1.40 & 0.83 & 0.07 & 10.10 & 0.72 & 0.39 \\
\hline \multicolumn{7}{|l|}{ Instruments } \\
\hline Single & 0.08 & 0.28 & 0 & 1 & 0.24 & 0.14 \\
\hline No dep. children, partner doesn't work or works $\mathrm{p} / \mathrm{t}$ & 0.19 & 0.39 & 0 & 1 & 0.34 & 0.19 \\
\hline No dep. children, partner works full time & 0.11 & 0.32 & 0 & 1 & 0.28 & 0.18 \\
\hline Dep. children $\leq 5$, partner doesn't work & 0.03 & 0.16 & 0 & 1 & 0.13 & 0.10 \\
\hline Dep. children $\leq 5$, partner works part time & 0.03 & 0.16 & 0 & 1 & 0.12 & 0.11 \\
\hline Dep. children $\leq 5$, partner works full time & 0.05 & 0.21 & 0 & 1 & 0.17 & 0.12 \\
\hline Dep. children $>5$, partner doesn't work or works $\mathrm{p} / \mathrm{t}$ & 0.25 & 0.43 & 0 & 1 & 0.37 & 0.24 \\
\hline Dep. children $>5$, partner works full time & 0.22 & 0.42 & 0 & 1 & 0.36 & 0.23 \\
\hline Single with dep. children & 0.04 & 0.19 & 0 & 1 & 0.16 & 0.10 \\
\hline
\end{tabular}

Table IIA: Waiting time regression results for all GPs 


\begin{tabular}{|c|c|c|c|c|c|c|c|c|}
\hline \multirow{3}{*}{$\begin{array}{l}\text { Independent variables } \\
\text { Total hours worked per week }\end{array}$} & \multirow{2}{*}{\multicolumn{2}{|c|}{$\begin{array}{l}(1) \\
\text { OLS }\end{array}$}} & \multirow{2}{*}{\multicolumn{2}{|c|}{$\begin{array}{c}\text { (2) } \\
\text { GP fixed effects }\end{array}$}} & \multirow{2}{*}{\multicolumn{2}{|c|}{$\begin{array}{l}\text { (3) } \\
\text { IV }\end{array}$}} & \multirow{2}{*}{\multicolumn{2}{|c|}{$\begin{array}{l}\text { (4) } \\
\text { FEIV }\end{array}$}} \\
\hline & & & & & & & & \\
\hline & $0.012^{* *}$ & $(0.005)$ & 0.006 & $(0.006)$ & $-0.066 * *$ & $(0.026)$ & $-0.125 * * *$ & $(0.043)$ \\
\hline \multicolumn{9}{|l|}{ Personal characteristics } \\
\hline Female & $0.872 * * *$ & $(0.172)$ & & & 0.217 & $(0.299)$ & & \\
\hline Age: $35-39$ [Excl: Under 35 years] & $0.618^{* * *}$ & $(0.202)$ & 0.293 & $(0.278)$ & $0.499 * *$ & $(0.228)$ & 0.162 & $(0.280)$ \\
\hline Age: $40-44$ & $0.897 * * *$ & $(0.232)$ & 0.297 & $(0.388)$ & $0.741 * * *$ & $(0.267)$ & 0.372 & $(0.389)$ \\
\hline Age: $45-49$ & $0.969 * * *$ & $(0.226)$ & 0.233 & $(0.453)$ & $0.998 * * *$ & $(0.246)$ & 0.637 & $(0.469)$ \\
\hline Age: $50-54$ & $0.963^{* * *}$ & $(0.225)$ & 0.163 & $(0.496)$ & $1.134^{* * *}$ & $(0.246)$ & 0.709 & $(0.527)$ \\
\hline Age: $55-59$ & $0.567^{* *}$ & $(0.233)$ & -0.293 & $(0.547)$ & $0.751^{* * *}$ & $(0.248)$ & 0.319 & $(0.588)$ \\
\hline Age: 60-64 & $0.427^{*}$ & $(0.246)$ & -0.466 & $(0.602)$ & 0.410 & $(0.280)$ & -0.106 & $(0.628)$ \\
\hline Age: 65 or over & 0.024 & $(0.288)$ & -0.783 & $(0.695)$ & -0.662 & $(0.415)$ & -0.900 & $(0.711)$ \\
\hline Length of std. private consultation (mins) & $0.153^{* * *}$ & $(0.015)$ & $0.096 * * *$ & $(0.018)$ & $0.253^{* * *}$ & $(0.020)$ & $0.081 * * *$ & $(0.019)$ \\
\hline Australian medical graduate & $1.176 * * *$ & $(0.156)$ & & & $0.740 * * *$ & $(0.171)$ & & \\
\hline Post graduate qualification/Fellowship & $0.716 * * *$ & $(0.128)$ & $0.557^{* * *}$ & $(0.192)$ & $0.698 * * *$ & $(0.162)$ & $0.454 * *$ & $(0.204)$ \\
\hline \multicolumn{9}{|l|}{ Practice characteristics } \\
\hline Tenure in practice (years) & $0.158 * * *$ & $(0.017)$ & $0.136 * * *$ & $(0.023)$ & $0.180 * * *$ & $(0.021)$ & $0.149 * * *$ & $(0.024)$ \\
\hline Tenure in practice (years) squared & $-0.003 * * *$ & $(0.001)$ & $-0.003 * * *$ & $(0.001)$ & $-0.004 * * *$ & $(0.001)$ & $-0.003 * * *$ & $(0.001)$ \\
\hline Total no. of GPs in the practice & $0.036^{* *}$ & $(0.017)$ & 0.005 & $(0.020)$ & $0.063^{* *}$ & $(0.024)$ & -0.004 & $(0.021)$ \\
\hline$\%$ of patients bulk-billed & 0.001 & $(0.002)$ & 0.004 & $(0.003)$ & 0.000 & $(0.003)$ & 0.003 & $(0.003)$ \\
\hline No. of nurses & $0.164^{* * *}$ & $(0.037)$ & $0.115^{* * *}$ & $(0.043)$ & $0.226 * * *$ & $(0.054)$ & $0.117^{* * *}$ & $(0.044)$ \\
\hline No. of allied health prof. \& admin. Staff & 0.003 & $(0.012)$ & -0.011 & $(0.013)$ & $0.055^{* * *}$ & $(0.021)$ & -0.013 & (0.013) \\
\hline Associate [Excl: Principal/partner] & -0.200 & $(0.183)$ & -0.120 & $(0.205)$ & $-0.684 * *$ & $(0.333)$ & $-0.403^{*}$ & $(0.234)$ \\
\hline Salaried or Contracted employee & $-0.733 * * *$ & $(0.162)$ & $-0.446 * *$ & $(0.208)$ & $-1.706 * * *$ & $(0.304)$ & $-0.866 * * *$ & $(0.260)$ \\
\hline Locum or other & $-0.877^{* * *}$ & $(0.208)$ & $-0.585^{* *}$ & $(0.247)$ & $-2.102 * * *$ & $(0.390)$ & $-1.024 * * *$ & $(0.302)$ \\
\hline \multicolumn{9}{|l|}{ Area level characteristics } \\
\hline Location (ASGC): Regional [Excl: City] & $1.800 * * *$ & $(0.174)$ & $1.623 * * *$ & $(0.287)$ & $1.937^{* * *}$ & $(0.215)$ & $1.730 * * *$ & (0.299) \\
\hline Location (ASGC): Remote & $1.558^{* * *}$ & $(0.423)$ & $1.123 * *$ & $(0.514)$ & $2.188^{* * *}$ & $(0.647)$ & $1.516^{* *}$ & $(0.607)$ \\
\hline SEIFA Index & $-0.006 * * *$ & $(0.001)$ & -0.002 & $(0.001)$ & $-0.010 * * *$ & $(0.001)$ & $-0.003^{*}$ & $(0.002)$ \\
\hline Percent of population under 5 yrs of age & -0.053 & $(0.047)$ & -0.044 & $(0.062)$ & -0.037 & $(0.063)$ & -0.039 & $(0.066)$ \\
\hline Percent of population above 65 yrs of age & $0.058 * * *$ & $(0.015)$ & $0.047^{* *}$ & $(0.024)$ & $0.060 * * *$ & $(0.016)$ & $0.049 * *$ & $(0.025)$ \\
\hline Min. distance to emergency department & $-0.056 * * *$ & $(0.018)$ & $-0.043^{*}$ & $(0.025)$ & $-0.088 * * *$ & $(0.024)$ & $-0.057^{* *}$ & $(0.028)$ \\
\hline Ratio of GPs to population (per 1,000 ) & $-0.179 * *$ & $(0.070)$ & -0.111 & $(0.086)$ & $-0.341 * * *$ & $(0.091)$ & -0.082 & $(0.087)$ \\
\hline Year fixed effects & Yes & & Yes & & Yes & & Yes & \\
\hline GP fixed effects & No & & Yes & & No & & Yes & \\
\hline \multicolumn{9}{|l|}{$y$} \\
\hline Observations & 14,544 & & 14,544 & & 14,544 & & 14,544 & \\
\hline R-squared & 0.185 & & 0.031 & & 0.164 & & - & \\
\hline Number of GPs & 3,561 & & 3,561 & & 3,561 & & 3,561 & \\
\hline \multicolumn{9}{|l|}{ First Stage statistics } \\
\hline F-stat of excluded instruments [P-value] & & & & & $41.09[0.000]$ & & $17.16[0.000]$ & \\
\hline Partial R-squared of excluded instruments & & & & & 0.048 & & 0.018 & \\
\hline Underidentification test P-value & & & & & 0.000 & & 0.000 & \\
\hline Endogeneity test $\mathrm{P}$-value & & & & & 0.000 & & 0.001 & \\
\hline
\end{tabular}

Notes: Robust std. errors clustered on GP in parenthesis. Coefficients for year effects and constant are omitted. ${ }^{* * *}, * *, *$ indicate significance at $1 \%, 5 \%$ and $10 \%$. 
Table IIB: First stage results - Effect of family characteristics on total hours worked per week

\begin{tabular}{|c|c|c|c|c|}
\hline \multirow[b]{2}{*}{ Independent variables } & \multicolumn{4}{|c|}{ All GPs } \\
\hline & \multicolumn{2}{|c|}{ IV } & \multicolumn{2}{|c|}{ FEIV } \\
\hline & \multicolumn{2}{|c|}{ (1) } & \multicolumn{2}{|c|}{$(2)$} \\
\hline \multicolumn{5}{|l|}{ Instruments } \\
\hline $\begin{array}{l}\text { No dep. children, partner doesn't work or works part time [Excl: } \\
\text { Single GP] }\end{array}$ & $-3.268 * * *$ & $(0.684)$ & -0.253 & $(0.436)$ \\
\hline No dep. children, partner works full time & -0.793 & $(0.668)$ & $1.295^{* * *}$ & $(0.442)$ \\
\hline Dep. children $\leq 5$, partner doesn't work & $-1.760 *$ & $(0.897)$ & $-1.282 *$ & (0.689) \\
\hline Dep. children $\leq 5$, partner works part time & $-4.984 * * *$ & $(0.970)$ & $-2.577 * * *$ & $(0.647)$ \\
\hline Dep. children $\leq 5$, partner works full time & $-11.144 * * *$ & $(0.779)$ & $-5.494 * * *$ & $(0.564)$ \\
\hline Dep. children > 5, partner doesn't work or works part time & $-1.583 * * *$ & $(0.602)$ & $-0.883 * *$ & $(0.406)$ \\
\hline Dep. children $>5$, partner works full time & $-5.566 * * *$ & $(0.610)$ & $-1.811 * * *$ & $(0.432)$ \\
\hline Single, Have dep. children & $-1.611^{*}$ & $(0.879)$ & -1.015 & $(0.674)$ \\
\hline Covariates & Yes & & Yes & \\
\hline Year fixed effects & Yes & & Yes & \\
\hline GP fixed effects & No & & Yes & \\
\hline Observations & 14,544 & & 14,544 & \\
\hline Centered R2 & 0.3857 & & 0.0723 & \\
\hline Number of GPs & 3,561 & & 3,561 & \\
\hline
\end{tabular}

Notes: Robust std. errors clustered on GP in parenthesis. Coefficients for covariates, year effects and constant are omitted. ${ }^{* * *}$, $* *, *$ indicate significance at $1 \%, 5 \%$ and $10 \%$ respectively 
Table III: Waiting time regression results using alternative measures of labour supply

\begin{tabular}{|c|c|c|c|c|}
\hline & \multicolumn{2}{|c|}{ (1) } & \multicolumn{2}{|c|}{ (2) } \\
\hline Measure of labour supply & \multicolumn{2}{|c|}{ IV } & \multicolumn{2}{|c|}{ FEIV } \\
\hline \multirow[t]{2}{*}{ A: Hours worked in direct patient care per week } & $-0.078 * *$ & $(0.032)$ & $-0.196 * * *$ & $(0.062)$ \\
\hline & \multicolumn{2}{|c|}{$[F=34.47]$} & \multicolumn{2}{|c|}{$[F=9.441]$} \\
\hline \multirow[t]{2}{*}{ B: No. of patients (visits) seen per week } & $-0.028 * * *$ & $(0.010)$ & $-0.045 * *$ & $(0.018)$ \\
\hline & \multicolumn{2}{|c|}{$[F=15.44]$} & \multicolumn{2}{|c|}{$[F=6.428]$} \\
\hline \multirow[t]{2}{*}{ C: Baseline results: Total hours worked per week } & $-0.066 * *$ & $(0.026)$ & $-0.125 * * *$ & (0.043) \\
\hline & \multicolumn{2}{|c|}{$[\mathrm{F}=41.09]$} & \multicolumn{2}{|c|}{$[F=17.16]$} \\
\hline
\end{tabular}

Notes: Complete tables are available on request. $* * *, * * *$ indicate significance at $1 \%, 5 \%$ and $10 \%$. F-statistic for the excluded instruments in the first stage are in square brackets.

Table IV: Robustness checks on sub-samples

\begin{tabular}{|c|c|c|c|c|}
\hline & \multicolumn{2}{|c|}{ (1) } & \multicolumn{2}{|c|}{ (2) } \\
\hline Sub-samples & \multicolumn{2}{|c|}{ IV } & \multicolumn{2}{|c|}{ FEIV } \\
\hline \multicolumn{5}{|l|}{ A: Bulk-billing } \\
\hline $80 \%$ or more patients bulk-billed & $-0.097 * *$ & $(0.047)$ & -0.120 & $(0.138)$ \\
\hline$(\mathrm{N}=5,212, \mathrm{n}=1,789)$ & \multicolumn{2}{|c|}{$[F=12.69]$} & \multicolumn{2}{|c|}{$[F=4.31]$} \\
\hline Less than $80 \%$ patients bulk-billed & -0.044 & $(0.027)$ & $-0.129 * * *$ & $(0.044)$ \\
\hline$(N=9,332, n=2,689)$ & \multicolumn{2}{|c|}{$[F=33.67]$} & \multicolumn{2}{|c|}{$[F=10.94]$} \\
\hline \multicolumn{5}{|l|}{ B: Female and male GPs } \\
\hline Female GPs & -0.042 & $(0.026)$ & $-0.096 * *$ & $(0.041)$ \\
\hline$(\mathrm{N}=7,211, \mathrm{n}=1,786)$ & \multicolumn{2}{|c|}{$[F=42.85]$} & \multicolumn{2}{|c|}{$[F=14.74]$} \\
\hline Male GPs & -0.090 & $(0.084)$ & -0.162 & $(0.141)$ \\
\hline$(\mathrm{N}=7,333, \mathrm{n}=1,775)$ & \multicolumn{2}{|c|}{$[F=4.247]$} & \multicolumn{2}{|c|}{$[F=2.794]$} \\
\hline \multicolumn{5}{|l|}{ C: Employed and self-employed GPs } \\
\hline Employed GPs & $-0.061 * *$ & $(0.024)$ & $-0.074 * *$ & $(0.038)$ \\
\hline$(\mathrm{N}=8,874, \mathrm{n}=2,586)$ & \multicolumn{2}{|c|}{$[F=42.04]$} & \multicolumn{2}{|c|}{$[F=13.91]$} \\
\hline Self-employed GPs (principals, partners or associates) & -0.085 & $(0.071)$ & $-0.222 *$ & $(0.128)$ \\
\hline$(N=5,670, n=1,664)$ & \multicolumn{2}{|c|}{$[F=5.06]$} & \multicolumn{2}{|c|}{$[F=3.36]$} \\
\hline \multicolumn{5}{|l|}{ D: Baseline results } \\
\hline Full estimation sample & $-0.066 * *$ & $(0.026)$ & $-0.125 * * *$ & $(0.043)$ \\
\hline$(\mathrm{N}=14,544, \mathrm{n}=3,561)$ & \multicolumn{2}{|c|}{$[F=41.09]$} & \multicolumn{2}{|c|}{$[F=17.16]$} \\
\hline
\end{tabular}

Notes: The table presents the coefficients on the total hours worked per week. In FEIV models, the number of observations were lesser due to the exclusion of singleton groups when sample is restricted to GPs bulk-billing $80 \%$ or more patients (430 observations dropped), bulk-billing less than $80 \%$ patients (393 observations dropped), and when sample is divided into employed (246 observations dropped) and self-employed GPs (310 observations dropped). Complete tables are available on request. $* * *, * *, *$ indicate significance at $1 \%, 5 \%$ and $10 \%$. F-statistic for the excluded instruments in the first stage are in square brackets. 


\section{Appendix}

\section{Table A1: Sample selection}

\begin{tabular}{|l|c|}
\hline Total observations in MABEL waves 1-7 & 24,609 \\
\hline Dropped & 10,065 \\
\hline Final sample & 14,544 \\
\hline Reasons for dropping: & 997 \\
\hline Missing information on total hours worked & 1,708 \\
\hline Missing information on waiting time & 970 \\
\hline Conflicting information on reported working hours & 299 \\
\hline Reports weekly total hours more than 75 or less than 4 & 330 \\
\hline $\begin{array}{l}\text { Reports average waiting time greater than 30 days } \\
\text { Missing information on covariates that enter waiting time equation or family characteristics } \\
\text { variables (used to construct instruments) }\end{array}$ & 4,196 \\
\hline GPs having two or fewer observations across seven waves & 1,565 \\
\hline TOTAL & 10,065 \\
\hline
\end{tabular}


Table A2: Descriptive statistics by gender, pooled across years (2008-2014)

\begin{tabular}{|c|c|c|c|c|c|c|c|c|}
\hline \multirow[b]{3}{*}{ Variable } & \multicolumn{4}{|c|}{ Female GPs } & \multicolumn{4}{|c|}{ Male GPs } \\
\hline & \multicolumn{4}{|c|}{$(N=7,211, n=1,786)$} & \multicolumn{4}{|c|}{$(N=7,333, n=1,775)$} \\
\hline & Mean & S D & S D & S D & Mean & S D & S D & S D \\
\hline & & Overall & Between & Within & & Overall & Between & Within \\
\hline Waiting time for you in practice & 4.28 & 5.55 & 4.80 & 2.83 & 3.76 & 5.64 & 5.16 & 2.61 \\
\hline Total hours worked per week & 31.64 & 12.20 & 11.18 & 5.11 & 43.35 & 12.35 & 11.21 & 5.40 \\
\hline Hours worked in direct patient care per week & 25.79 & 10.63 & 9.76 & 4.54 & 36.47 & 11.26 & 10.21 & 5.29 \\
\hline No. of patients (visits) seen per week & 85.38 & 45.41 & 41.13 & 20.37 & 135.21 & 56.47 & 51.95 & 25.33 \\
\hline \multicolumn{9}{|l|}{ Personal characteristics } \\
\hline Age: Under 35 & 0.12 & 0.33 & 0.34 & 0.14 & 0.05 & 0.22 & 0.23 & 0.10 \\
\hline Age: $35-39$ & 0.14 & 0.34 & 0.29 & 0.21 & 0.08 & 0.26 & 0.23 & 0.15 \\
\hline Age: $40-44$ & 0.15 & 0.36 & 0.28 & 0.23 & 0.10 & 0.29 & 0.24 & 0.19 \\
\hline Age: $45-49$ & 0.17 & 0.38 & 0.29 & 0.25 & 0.14 & 0.35 & 0.27 & 0.23 \\
\hline Age: $50-54$ & 0.18 & 0.38 & 0.28 & 0.26 & 0.18 & 0.39 & 0.29 & 0.26 \\
\hline Age: $55-59$ & 0.13 & 0.34 & 0.25 & 0.22 & 0.18 & 0.39 & 0.29 & 0.26 \\
\hline Age: $60-64$ & 0.08 & 0.26 & 0.20 & 0.17 & 0.13 & 0.33 & 0.25 & 0.22 \\
\hline Age: 65 or over & 0.03 & 0.18 & 0.16 & 0.09 & 0.14 & 0.35 & 0.33 & 0.14 \\
\hline Length of std. private consultation & 16.89 & 4.16 & 3.70 & 2.05 & 14.76 & 3.52 & 3.19 & 1.70 \\
\hline Australian medical graduate & 0.78 & 0.42 & 0.44 & 0.00 & 0.71 & 0.45 & 0.47 & 0.00 \\
\hline Have post graduate qualification/Fellowship & 0.64 & 0.48 & 0.45 & 0.18 & 0.58 & 0.49 & 0.47 & 0.15 \\
\hline \multicolumn{9}{|l|}{ Practice characteristics } \\
\hline Tenure in practice (years) & 7.02 & 7.82 & 7.17 & 2.73 & 10.94 & 11.09 & 10.46 & 3.62 \\
\hline Total no. of GPs in the practice & 7.99 & 4.02 & 3.69 & 1.86 & 7.53 & 4.30 & 3.94 & 1.97 \\
\hline$\%$ of patients bulk-billed & 56.10 & 30.51 & 27.84 & 12.89 & 64.94 & 29.15 & 27.12 & 11.67 \\
\hline No. of nurses in the practice & 2.34 & 1.86 & 1.65 & 0.93 & 2.45 & 1.94 & 1.76 & 0.90 \\
\hline $\begin{array}{l}\text { No. of allied health prof. \& administrative staff in } \\
\text { practice }\end{array}$ & 6.26 & 4.10 & 3.45 & 2.36 & 6.09 & 4.30 & 3.71 & 2.39 \\
\hline Employment type: Principal or partner & 0.16 & 0.36 & 0.33 & 0.15 & 0.41 & 0.49 & 0.44 & 0.21 \\
\hline Employment type: Associate & 0.09 & 0.29 & 0.22 & 0.18 & 0.12 & 0.32 & 0.26 & 0.19 \\
\hline Employment type: Salaried or Contracted employee & 0.71 & 0.45 & 0.39 & 0.23 & 0.43 & 0.50 & 0.45 & 0.23 \\
\hline Employment type: Locum or other & 0.04 & 0.19 & 0.14 & 0.14 & 0.04 & 0.20 & 0.17 & 0.12 \\
\hline \multicolumn{9}{|l|}{ Area characteristics } \\
\hline Location: City & 0.71 & 0.45 & 0.44 & 0.14 & 0.62 & 0.49 & 0.47 & 0.13 \\
\hline Location: Regional & 0.27 & 0.44 & 0.43 & 0.14 & 0.35 & 0.48 & 0.46 & 0.13 \\
\hline Location: Remote & 0.02 & 0.15 & 0.15 & 0.06 & 0.03 & 0.18 & 0.18 & 0.05 \\
\hline SEIFA Index & 1028.62 & 74.51 & 71.01 & 25.19 & 1003.77 & 72.29 & 68.86 & 21.19 \\
\hline Percent of population under $5 \mathrm{yrs}$ of age & 5.98 & 1.42 & 1.34 & 0.56 & 6.08 & 1.37 & 1.29 & 0.48 \\
\hline Percent of population above 65 yrs of age & 13.52 & 4.78 & 4.47 & 1.78 & 14.26 & 5.10 & 4.90 & 1.55 \\
\hline Min. distance to emergency department & 4.62 & 3.44 & 3.16 & 1.37 & 4.62 & 3.62 & 3.41 & 1.19 \\
\hline Ratio of GPs to population (per 1,000 ) & 1.47 & 0.89 & 0.76 & 0.41 & 1.32 & 0.77 & 0.67 & 0.37 \\
\hline \multirow{2}{*}{\multicolumn{9}{|c|}{ Instruments }} \\
\hline & & & & & & & & \\
\hline Single & 0.10 & 0.30 & 0.27 & 0.15 & 0.07 & 0.25 & 0.22 & 0.14 \\
\hline $\begin{array}{l}\text { No dep. children, partner doesn't work or works part } \\
\text { time }\end{array}$ & 0.10 & 0.30 & 0.26 & 0.15 & 0.28 & 0.45 & 0.39 & 0.22 \\
\hline No dep. children, partner works full time & 0.14 & 0.35 & 0.31 & 0.20 & 0.08 & 0.28 & 0.23 & 0.17 \\
\hline Dep. children $\leq 5$, partner doesn't work & 0.02 & 0.12 & 0.09 & 0.08 & 0.04 & 0.19 & 0.16 & 0.12 \\
\hline Dep. children $\leq 5$, partner works part time & 0.02 & 0.13 & 0.09 & 0.09 & 0.03 & 0.18 & 0.14 & 0.12 \\
\hline Dep. children $\leq 5$, partner works full time & 0.08 & 0.28 & 0.23 & 0.16 & 0.01 & 0.10 & 0.07 & 0.07 \\
\hline $\begin{array}{l}\text { Dep. children }>5 \text {, partner doesn't work or works part } \\
\text { time }\end{array}$ & 0.13 & 0.34 & 0.28 & 0.20 & 0.37 & 0.48 & 0.41 & 0.26 \\
\hline Dep. children $>5$, partner works full time & 0.35 & 0.48 & 0.40 & 0.26 & 0.10 & 0.30 & 0.25 & 0.18 \\
\hline Single, Dep. children & 0.06 & 0.23 & 0.20 & 0.11 & 0.02 & 0.14 & 0.11 & 0.09 \\
\hline
\end{tabular}


Table A3: Transition probabilities of GPs moving into different family types (instrument categories) each year

\begin{tabular}{|c|c|c|c|c|c|c|c|c|c|c|}
\hline & & & & & Instruments & & & & & \\
\hline Instruments & 1 & 2 & 3 & 4 & 5 & 6 & 7 & 8 & 9 & Total \\
\hline \multicolumn{11}{|l|}{$=$} \\
\hline 1 & 71.22 & 8.31 & 8.68 & 0.12 & 0.5 & 0.37 & 4.96 & 3.47 & 2.36 & 100 \\
\hline 2 & 2.9 & 86.06 & 5.46 & 0.06 & 0.11 & 0.11 & 4.66 & 0.34 & 0.28 & 100 \\
\hline 3 & 5.48 & 13.03 & 69.88 & 0.19 & 0.09 & 0.57 & 3.59 & 6.99 & 0.19 & 100 \\
\hline 4 & 1.33 & 0.66 & 0 & 57.81 & 14.95 & 3.32 & 19.6 & 1.66 & 0.66 & 100 \\
\hline 5 & 2.09 & 1.05 & 0 & 10.8 & 50.17 & 8.71 & 20.56 & 5.23 & 1.39 & 100 \\
\hline 6 & 1.5 & 0 & 0.75 & 2.81 & 4.87 & 64.61 & 2.06 & 23.03 & 0.37 & 100 \\
\hline 7 & 1.58 & 7.94 & 0.45 & 0.24 & 0.2 & 0.08 & 80.85 & 7.73 & 0.93 & 100 \\
\hline 8 & 1.74 & 1.05 & 5.86 & 0.05 & 0.09 & 0.27 & 9.19 & 80.6 & 1.14 & 100 \\
\hline 9 & 11.5 & 0.27 & 1.87 & 0 & 0.27 & 0.53 & 4.55 & 6.15 & 74.87 & 100 \\
\hline \multicolumn{11}{|l|}{ 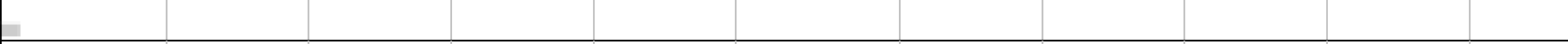 } \\
\hline Total & 8.4 & 19.88 & 10.8 & 2.36 & 2.35 & 4.1 & 25.62 & 22.78 & 3.7 & 100 \\
\hline
\end{tabular}

Notes: The rows reflect the values in period $(t)$ and the columns reflect the values in period $(t+1)$.

Key

\begin{tabular}{|c|l|}
\hline Number & Description \\
\hline 1 & Single GP \\
\hline 2 & No dep. children, partner doesn't work or works part time \\
\hline 3 & No dep. children, partner works full time \\
\hline 4 & Dep. children $\leq 5$, partner doesn't work \\
\hline 5 & Dep. children $\leq 5$, partner works part time \\
\hline 6 & Dep. children $\leq 5$, partner works full time \\
\hline 7 & Dep. children $>5$, partner doesn't work or works part time \\
\hline 8 & Dep. children $>5$, partner works full time \\
\hline 9 & Single, Dep. children \\
\hline
\end{tabular}


Table A4: First stage results by gender- Effect of family characteristics on total hours worked per week

\begin{tabular}{|c|c|c|c|c|c|c|c|c|}
\hline \multirow[b]{2}{*}{ Independent variables } & \multicolumn{4}{|c|}{ Female GPs } & \multicolumn{4}{|c|}{ Male GPs } \\
\hline & \multicolumn{2}{|l|}{ IV } & \multicolumn{2}{|c|}{ FEIV } & \multicolumn{2}{|l|}{ IV } & \multicolumn{2}{|c|}{ FEIV } \\
\hline & \multicolumn{2}{|c|}{ (1) } & \multicolumn{2}{|c|}{$(2)$} & \multicolumn{2}{|l|}{ (3) } & \multicolumn{2}{|c|}{ (4) } \\
\hline \multicolumn{9}{|l|}{ Instruments } \\
\hline $\begin{array}{l}\text { No dep. children, partner doesn't work or works part time [Excl: } \\
\text { Single GP] }\end{array}$ & $-2.626 * * *$ & $(1.003)$ & -0.260 & $(0.688)$ & -1.341 & $(0.928)$ & 0.203 & $(0.550)$ \\
\hline No dep. children, partner works full time & $-1.642^{*}$ & $(0.867)$ & $1.360 * *$ & $(0.638)$ & 0.462 & $(0.928)$ & $1.103^{*}$ & $(0.597)$ \\
\hline Dep. children $\leq 5$, partner doesn't work & -2.249 & $(1.762)$ & -1.607 & $(1.250)$ & -0.334 & $(1.078)$ & -0.853 & $(0.788)$ \\
\hline Dep. children $\leq 5$, partner works part time & $-8.988 * * *$ & $(1.523)$ & $-4.635 * * *$ & (1.075) & $-1.978^{*}$ & $(1.190)$ & -1.118 & $(0.773)$ \\
\hline Dep. children $\leq 5$, partner works full time & $-12.958 * * *$ & $(0.894)$ & $-6.552 * * *$ & $(0.733)$ & -0.811 & $(2.149)$ & $-3.083 * * *$ & $(0.914)$ \\
\hline Dep. children > 5, partner doesn't work or works part time & $-3.434 * * *$ & $(0.854)$ & $-1.760 * * *$ & $(0.648)$ & 1.214 & $(0.832)$ & 0.001 & $(0.513)$ \\
\hline Dep. children > 5, partner works full time & $-8.251 * * *$ & $(0.770)$ & $-3.054 * * *$ & $(0.607)$ & $2.043^{* *}$ & $(0.941)$ & 0.490 & $(0.596)$ \\
\hline Single, Have dep. children & $-3.349 * * *$ & $(1.021)$ & $-1.633^{*}$ & $(0.876)$ & 1.779 & $(1.674)$ & 0.037 & $(1.082)$ \\
\hline Covariates & Yes & & Yes & & Yes & & Yes & \\
\hline Year fixed effects & Yes & & Yes & & Yes & & Yes & \\
\hline GP fixed effects & No & & Yes & & No & & Yes & \\
\hline Observations & 7,211 & & 7,211 & & 7,333 & & 7,333 & \\
\hline Centered R2 & 0.2939 & & 0.0835 & & 0.2731 & & 0.0893 & \\
\hline Number of GPs & 1,786 & & 1,786 & & 1,775 & & 1,775 & \\
\hline \multicolumn{9}{|l|}{ Important statistics } \\
\hline F-stat of excluded instruments [P-value] & $42.85[0.000]$ & & $14.74[0.000]$ & & $4.247[0.000]$ & & $2.794[0.004]$ & \\
\hline Partial R-squared of excluded instruments & 0.100 & & 0.038 & & 0.011 & & 0.003 & \\
\hline Underidentification test P-value & 0.000 & & 0.000 & & 0.000 & & 0.023 & \\
\hline Endogeneity test P-value & 0.007 & & 0.009 & & 0.170 & & 0.216 & \\
\hline
\end{tabular}

Notes: Robust std. errors clustered on GP in parenthesis. Coefficients for covariates, year effects and constant are omitted $* * *, * *, *$ indicate significance at $1 \%, 5 \%$ and $10 \%$ respectively

This article is protected by copyright. All rights reserved. 
Table A5: Waiting time regression results, excluding bulk-billing variable from covariates

\begin{tabular}{|c|c|c|c|c|c|c|c|c|}
\hline \multirow{3}{*}{$\begin{array}{l}\text { Independent variables } \\
\text { Total hours worked per week }\end{array}$} & \multirow{2}{*}{\multicolumn{2}{|c|}{$\begin{array}{l}\text { (1) } \\
\text { OLS }\end{array}$}} & \multirow{2}{*}{\multicolumn{2}{|c|}{$\begin{array}{c}\text { (2) } \\
\text { GP fixed effects }\end{array}$}} & \multirow{2}{*}{\multicolumn{2}{|c|}{$\begin{array}{l}\text { (3) } \\
\text { IV }\end{array}$}} & \multirow{2}{*}{\multicolumn{2}{|c|}{$\begin{array}{l}\text { (4) } \\
\text { FEIV }\end{array}$}} \\
\hline & & & & & & & & \\
\hline & $0.012^{* * *}$ & $(0.005)$ & 0.006 & $(0.006)$ & $-0.066 * *$ & $(0.026)$ & $-0.124^{* * *}$ & (0.043) \\
\hline \multicolumn{9}{|l|}{ Personal characteristics } \\
\hline Female & $0.870^{* * *}$ & $(0.172)$ & - & & 0.216 & $(0.300)$ & - & \\
\hline Age: 35-39 [Excl: Under 35 years] & $0.616^{* * *}$ & $(0.202)$ & 0.272 & $(0.277)$ & $0.499 * *$ & $(0.228)$ & 0.146 & $(0.280)$ \\
\hline Age: $40-44$ & $0.896 * * *$ & $(0.232)$ & 0.272 & $(0.386)$ & $0.741^{* * *}$ & $(0.267)$ & 0.351 & $(0.387)$ \\
\hline Age: $45-49$ & $0.968 * * *$ & $(0.226)$ & 0.209 & $(0.451)$ & $1.000 * * *$ & $(0.245)$ & 0.617 & $(0.467)$ \\
\hline Age: $50-54$ & $0.962 * * *$ & $(0.225)$ & 0.139 & $(0.493)$ & $1.136 * * *$ & $(0.245)$ & 0.689 & $(0.524)$ \\
\hline Age: $55-59$ & $0.567^{* *}$ & $(0.233)$ & -0.316 & $(0.545)$ & $0.752^{* * *}$ & (0.248) & 0.300 & (0.585) \\
\hline Age: 60-64 & $0.428^{*}$ & $(0.246)$ & -0.486 & $(0.600)$ & 0.412 & $(0.279)$ & -0.122 & $(0.626)$ \\
\hline Age: 65 or over & 0.027 & $(0.288)$ & -0.803 & $(0.694)$ & -0.656 & $(0.412)$ & -0.913 & $(0.709)$ \\
\hline Length of std. private consultation (min) & $0.153^{* * *}$ & $(0.015)$ & $0.095 * * *$ & $(0.018)$ & $0.253^{* * *}$ & $(0.020)$ & $0.081^{* * *}$ & $(0.019)$ \\
\hline Australian medical graduate & $1.169^{* * *}$ & $(0.154)$ & - & & $0.736^{* * *}$ & $(0.171)$ & - & \\
\hline Have post graduate qualification/Fellowship & $0.716^{* * *}$ & $(0.128)$ & $0.567^{* * *}$ & $(0.193)$ & $0.698 * * *$ & $(0.162)$ & $0.464^{* *}$ & $(0.204)$ \\
\hline \multicolumn{9}{|l|}{ Practice characteristics } \\
\hline Tenure in practice (years) & $0.158^{* * *}$ & $(0.017)$ & $0.137^{* * *}$ & $(0.023)$ & $0.180^{* * *}$ & $(0.021)$ & $0.150 * * *$ & $(0.024)$ \\
\hline Tenure in practice (years) squared & $-0.003^{* * *}$ & $(0.001)$ & $-0.003 * * *$ & $(0.001)$ & $-0.004 * * *$ & $(0.001)$ & $-0.003 * * *$ & $(0.001)$ \\
\hline Total no. of GPs in the practice & $0.036 * *$ & $(0.017)$ & 0.004 & $(0.020)$ & $0.063 * *$ & $(0.024)$ & -0.005 & (0.021) \\
\hline No. of nurses in the practice & $0.164 * * *$ & $(0.037)$ & $0.116^{* * *}$ & $(0.043)$ & $0.226 * * *$ & $(0.054)$ & $0.118^{* * *}$ & $(0.044)$ \\
\hline No. of allied health prof. \& admin. staff in practice & 0.003 & $(0.012)$ & -0.011 & $(0.013)$ & $0.055^{* * *}$ & $(0.021)$ & -0.013 & (0.013) \\
\hline Employment type: Associate [Excl: Principal or partner] & -0.201 & (0.183) & -0.123 & $(0.205)$ & $-0.685^{* *}$ & $(0.333)$ & $-0.405 *$ & (0.234) \\
\hline Employment type: Salaried or Contracted employee & $-0.732 * * *$ & (0.162) & $-0.447^{* *}$ & $(0.208)$ & $-1.705^{* * *}$ & $(0.304)$ & $-0.864 * * *$ & $(0.260)$ \\
\hline Employment type: Locum or other & $-0.876^{* * *}$ & $(0.208)$ & $-0.581 * *$ & $(0.247)$ & $-2.102^{* * *}$ & $(0.390)$ & $-1.017^{* * *}$ & $(0.301)$ \\
\hline \multicolumn{9}{|l|}{ (2) } \\
\hline \multicolumn{9}{|l|}{ Area level characteristics } \\
\hline Location (ASGC): Regional [Excl: City] & $1.795^{* * *}$ & $(0.172)$ & $1.597^{* * *}$ & $(0.286)$ & $1.931^{* * *}$ & $(0.210)$ & $1.709 * * *$ & $(0.297)$ \\
\hline Location (ASGC): Remote & $1.553^{* * *}$ & $(0.423)$ & $1.119^{* *}$ & $(0.512)$ & $2.181^{* * *}$ & $(0.645)$ & $1.510^{* *}$ & $(0.604)$ \\
\hline SEIFA Index & $-0.007 * * *$ & (0.001) & $-0.003^{*}$ & $(0.001)$ & $-0.010 * * *$ & $(0.001)$ & $-0.003 * *$ & $(0.002)$ \\
\hline Percent of population under 5 yrs of age & -0.052 & $(0.047)$ & -0.043 & $(0.062)$ & -0.036 & $(0.064)$ & -0.039 & $(0.066)$ \\
\hline Percent of population above $65 \mathrm{yrs}$ of age & $0.058 * * *$ & (0.015) & $0.048^{* *}$ & $(0.024)$ & $0.060 * * *$ & (0.016) & $0.050^{* *}$ & (0.025) \\
\hline Min. distance to emergency department & $-0.056 * * *$ & $(0.018)$ & -0.042 & $(0.025)$ & $-0.088 * * *$ & $(0.024)$ & $-0.056 * *$ & $(0.028)$ \\
\hline Ratio of GPs to population (per 1,000 ) & $-0.180 * * *$ & $(0.070)$ & -0.117 & $(0.086)$ & $-0.342 * * *$ & $(0.091)$ & -0.087 & $(0.087)$ \\
\hline Year fixed effects & Yes & & Yes & & Yes & & Yes & \\
\hline GP fixed effects & No & & Yes & & No & & Yes & \\
\hline Observations & 14,544 & & 14,544 & & 14,544 & & 14.544 & \\
\hline R-squared & 0.185 & & 0.030 & & 0.164 & & - & \\
\hline Number of GPs & 3,561 & & 3,561 & & 3,561 & & 3,561 & \\
\hline & & & & & & & & \\
\hline \multicolumn{9}{|l|}{ First Stage statistics } \\
\hline F-stat of excluded instruments [P-value] & & & & & $40.84[0.000]$ & & $17.16[0.000]$ & \\
\hline Partial R-squared of excluded instruments & & & & & 0.048 & & 0.018 & \\
\hline Underidentification test P-value & & & & & 0.000 & & 0.000 & \\
\hline Endogeneity test P-value & & & & & 0.000 & & 0.001 & \\
\hline
\end{tabular}

Notes: Robust std. errors clustered on GP in parenthesis. Coefficients for covariates, year effects and constant are omitted $* * *$, $* *, *$ indicate significance at $1 \%, 5 \%$ and $10 \%$ respectively 
Table A6: Sensitivity to different waiting time cut-offs

\begin{tabular}{|c|c|c|c|c|}
\hline & \multicolumn{2}{|c|}{ (1) } & \multicolumn{2}{|c|}{ (2) } \\
\hline Waiting time cut-offs & \multicolumn{2}{|c|}{ IV } & \multicolumn{2}{|c|}{ FEIV } \\
\hline Dropping GP-year observations in top and bottom $1 \%$ of waiting time distribution & $-0.073 * *$ & (0.029) & $-0.178 * * *$ & $(0.051)$ \\
\hline$(\mathrm{N}=14,697)$ & \multicolumn{2}{|c|}{$[F=41.05]$} & \multicolumn{2}{|c|}{$[F=16.89]$} \\
\hline Dropping GP-year observations if waiting time $>25$ days $(\mathrm{N}=14,287)$ & $-0.062 * * *$ & $(0.021)$ & $-0.129 * * *$ & $(0.037)$ \\
\hline Dropping GP-year observations if waiting time $>15$ days $(\mathrm{N}=13,781)$ & $-0.047 * * *$ & $(0.016)$ & $-0.074 * * *$ & $(0.028)$ \\
\hline ( $6.2 \%$ of non-missing observations on waiting time dropped) & \multicolumn{2}{|c|}{$[F=38.86]$} & \multicolumn{2}{|c|}{$[\mathrm{F}=16.47]$} \\
\hline Baseline: Dropping GP-year observations if waiting time $>30$ days $(N=14,544)$ & $-0.066 * *$ & $(0.026)$ & $-0.125 * * *$ & $(0.043)$ \\
\hline$\overline{(1.6 \% \text { of non-missing observations on waiting time dropped) }}$ & \multicolumn{2}{|c|}{$[F=41.09]$} & \multicolumn{2}{|c|}{$[F=17.16]$} \\
\hline
\end{tabular}

Notes: The table only presents the coefficients on the total hours worked per week. In all models the outliers/cut-offs for total hours worked is defined as the baseline specification, i.e. GP-year observations were excluded if total hours worked per week were below 4 hours or greater than 75 hours. Complete tables are available on request. $* * *, * *$ indicate significance at $1 \%, 5 \%$ and $10 \%$. F-statistic for the excluded instruments in the first stage are in square brackets. 


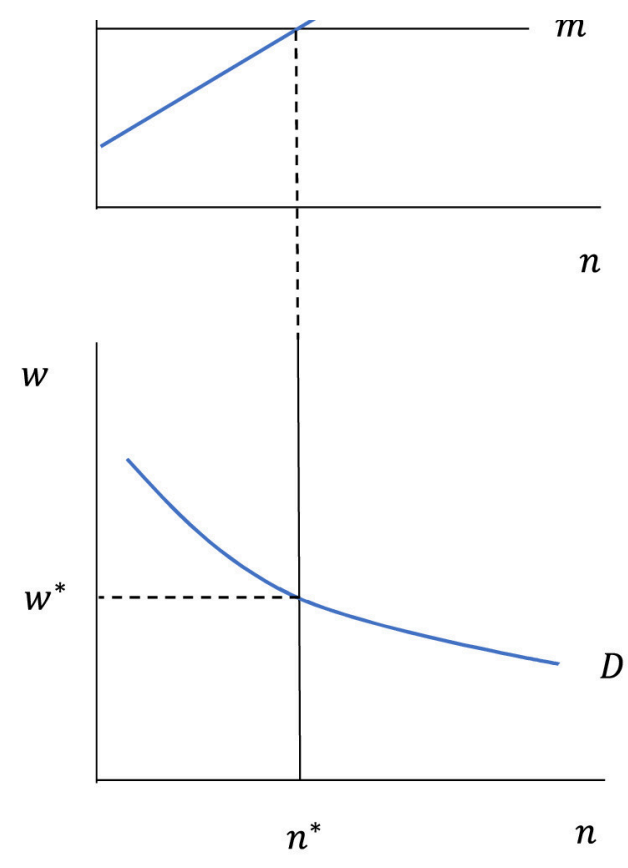

hec_3782_figure 1.eps

This article is protected by copyright. All rights reserved. 


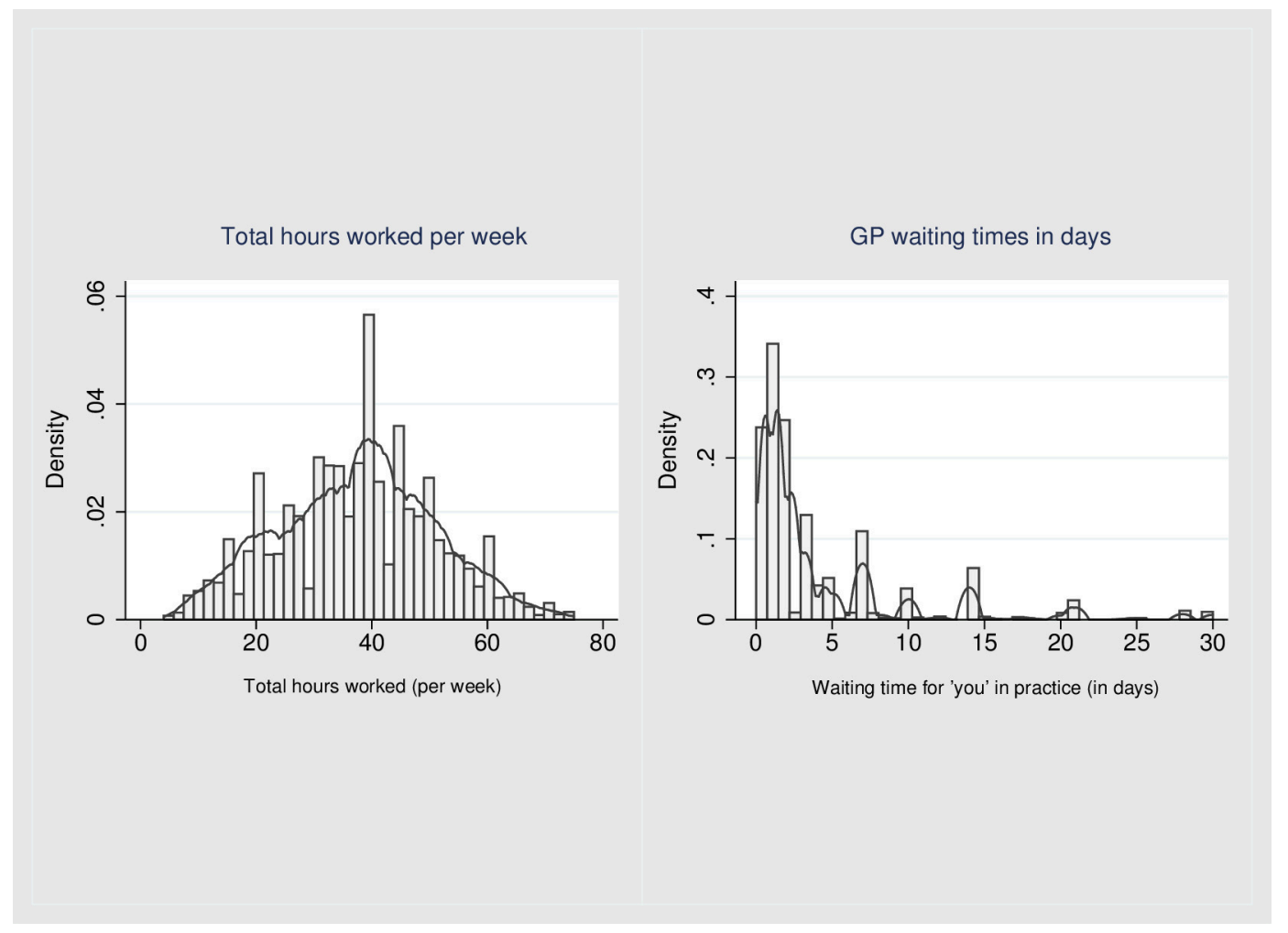

hec_3782_figure 2.eps

This article is protected by copyright. All rights reserved. 


\section{University Library}

\section{- M M I N E R VA A gateway to Melbourne's research publications}

Minerva Access is the Institutional Repository of The University of Melbourne

Author/s:

Swami, M;Gravelle, H;Scott, A;Williams, J

Title:

Hours worked by general practitioners and waiting times for primary care

Date:

2018-10-01

Citation:

Swami, M., Gravelle, H., Scott, A. \& Williams, J. (2018). Hours worked by general practitioners and waiting times for primary care. HEALTH ECONOMICS, 27 (10), pp.1513-1532. https://doi.org/10.1002/hec.3782.

Persistent Link:

http://hdl.handle.net/11343/284132 